\title{
Microwave-Assisted Synthesis of the Flexible Iron- Based MIL-88B Metal-Organic Framework for Advanced Energetic Systems
}

\section{Mahmoud Y. Zorainy}

Polytechnique Montréal

\section{Serge Kaliaguine}

Laval University

\section{Mohamed Gobara}

Military Technical College (MTC)

Sherif Elbasuney

Military Technical College (MTC)

Daria C. Boffito ( $\nabla$ daria-camilla.boffito@polymtl.ca )

Polytechnique Montréal https://orcid.org/0000-0002-5252-5752

\section{Research Article}

Keywords: MIL-88B(Fe), Metal-Organic Framework, MOF, Energetic Systems, Catalyzed propellant, Ammonium perchlorate, Thermal behavior.

Posted Date: December 22nd, 2021

DOI: https://doi.org/10.21203/rs.3.rs-1182353/v1

License: (c) (i) This work is licensed under a Creative Commons Attribution 4.0 International License. Read Full License 


\title{
Microwave-assisted Synthesis of the Flexible Iron-based MIL-88B Metal- Organic Framework for Advanced Energetic Systems
}

\author{
Mahmoud Y. Zorainy, ${ }^{\mathrm{a}, \mathrm{b}}$ Serge Kaliaguine, ${ }^{\mathrm{c}}$ Mohamed Gobara, ${ }^{\mathrm{b}}$ Sherif Elbasuney,d, Daria. C. \\ Boffito $^{\text {a }}$ \\ ${ }^{a}$ Chemical Engineering Department, Polytechnique Montréal, Montréal, H3C 3A7 (Canada) \\ ${ }^{b}$ Chemical Engineering Department, Military Technical College (MTC), Cairo (Egypt) \\ ${ }^{c}$ Chemical Engineering Department, Laval University, Québec, QC G1V 0A6 (Canada) \\ ${ }^{d}$ Nanotechnology Research Center, Military Technical College (MTC), Cairo (Egypt)
}

\begin{abstract}
The 3D metal-organic framework(MOF), MIL-88B, built from the trivalent metal ions and the ditopic 1,4-Benzene dicarboxylic acid linker $\left(\mathrm{H}_{2} \mathrm{BDC}\right)$, distinguishes itself from the other MOFs for its flexibility and high thermal stability. MIL-88B was synthesized by a rapid microwaveassisted solvothermal method at high power $(850 \mathrm{~W})$. The iron-based MIL-88B $\left[\mathrm{Fe}_{3}\right.$.O.Cl. $\left(\mathrm{O}_{2} \mathrm{C}-\right.$ $\left.\left.\mathrm{C}_{6} \mathrm{H}_{4}-\mathrm{CO}_{2}\right)_{3}\right]$ exposed oxygen and iron content of $29 \%$ and $24 \%$, respectively, which of fers unique properties as an oxygen-rich catalyst for energetic systems. Upon dispersion in an organic solvent and integration into ammonium perchlorate (AP) (the universal oxidizer for energetic systems), the dispersion of the MOF particles into the AP energetic matrix was uniform (investigated via elemental mapping using an EDX detector). Therefore, MIL- $88 \mathrm{~B}(\mathrm{Fe})$ could probe AP decomposition with the exclusive formation of mono-dispersed $\mathrm{Fe}_{2} \mathrm{O}_{3}$ nanocatalyst during the AP decomposition. The evolved nanocatalyst can offer superior combustion characteristics. XRD pattern for the MIL-88B(Fe) framework TGA residuals confirmed the formation of $\alpha-\mathrm{Fe}_{2} \mathrm{O}_{3}$ nanocatalyst as a final product. The catalytic efficiency of MIL- $88 \mathrm{~B}(\mathrm{Fe})$ on AP thermal behavior was assessed via DSC and TGA. AP solely demonstrated a decomposition enthalpy of $733 \mathrm{~J} \mathrm{~g}^{-1}$, while AP/MIL-88B(Fe) showed a $66 \%$ higher decomposition enthalpy of $1218 \mathrm{~J} \mathrm{~g}^{-1}$; the main exothermic decomposition temperature was decreased by $71^{\circ} \mathrm{C}$. Besides, MIL-88B(Fe) resulted in a decrease in AP decomposition activation energy by $23 \%$ and $25 \%$ using Kissinger and Kissinger-Akahira-Sunose (KAS) models, respectively.
\end{abstract}

Keywords: MIL-88B(Fe), Metal-Organic Framework, MOF, Energetic Systems, Catalyzed propellant, Ammonium perchlorate, Thermal behavior. 


\section{Introduction}

Metal-organic frameworks (MOFs) are highly porous crystalline materials with large, accessible cages of regular shapes that confer unusually high surface area and pore volume. Such structures are capable of entrapping different molecules within their cavities for multiple purposes. They were found to be beneficial in a wide range of applications, whereby gas storage [1,2], separation [3-5], and heterogeneous catalysis [6, 7] are the most significant.[8]

Among the different generations of MOFs, the second and third generations ( $2 \mathrm{G}$ and $3 \mathrm{G}$, respectively) recently attracted more attention. MOFs belonging to the $2 \mathrm{G}$ are known to be robust structures that extend in the two- or three- dimensions to provide a permanent porosity with potential for various applications such as guest capture and release as well as sensing. [9, 10] The $3 \mathrm{G}$ MOFs are more attractive as their structures were proved to be soft and dynamic. Materials comprised in this subclass display reversible flexing (breathing) that takes place due to the presence of external chemical or physical stimuli such as guest encapsulation/elimination, temperature, pressure, light, or electric field.[1,10]

In March 2021, the Cambridge Crystallographic Data Centre (CDCC) announced the existence of more than 100,000 registered entries under the MOF subset.[11] The highly flexible MIL-88B framework has attracted numerous research groups' attention for its distinctive capability of expressing crystal transformation depending on the surrounding environment. MIL-88 refers to the formation of a 3D structure, whereby the trigonal prismatic metal cluster is formed from three trivalent metal centers and is connected to a ditopic linker, preserving the same parent topology.[12, 13] The letter in the designation indicates the type of this ditopic linker, whereby A denotes the use of fumaric acid (MIL-88A), B stands for 1,4-Benzene dicarboxylic acid (BDC, MIL-88B), C for 2,6-naphthalene dicarboxylic acid (NDC, MIL-88C), and D for 4,4'-biphenyl dicarboxylic acid (BPDC, MIL-88D).[13]

MIL-88B was initially reported to be built from the trinuclear oxo-centered chromium cluster and the dicarboxylate linker, giving a structural formula of $\left[\mathrm{M}_{3} \mathrm{OI}\right.$. $(\mathrm{BDC})_{3} . \mathrm{X}$, where $\mathrm{M}$ represents the trivalent metal cation, and $\mathrm{X}$ can be either $\mathrm{F}, \mathrm{Cl}$, or $\mathrm{OH}$ depending on the synthesis conditions] (Figure S1).[12, 13] It was reported that this framework occupies the topology of the acs net with the $P-\overline{6} 2 c$ space group, in which the voids within such a structure are composed of channels and not cages. Figure 1-a displays the structure of MIL-88B along the a-axis. Figure 1-b, where the structure is viewed along the c-axis, displays the channels within the framework.

The MIL-88B framework, with its known flexibility, expresses what is known as the "Breathing effect," in which the MOF crystals are capable of shrinking and swelling reversibly.[14-17] This change modifies the unit cell capacity of the framework, thus affecting the size of the channels without destruction or decomposition of the structure (Figure 1-c).[16, 17] Such a phenomenon is rarely found in solid crystals, making this MOF's capability an exciting research subject. Furthermore, on the macroscopic scale, the resulting MIL-88B(Fe) crystals may occupy different 
forms ranging from hexagonal bipyramids (diamond-like crystals) to hexagonal prisms (rod-like crystals), depending on the synthesis conditions (Figure 1-d).[18, 19]

As mentioned above, MIL-88B was first synthesized from the trivalent chromium ions; other metals were, however, incorporated in the preparation of this material, such as Sc [20-22], V [23], Mn [24], and Fe [12, 13, 15]. Recently, with the increasing numbers of studies on other flexible MOF materials, Fe-based MOFs have been sought for many applications because of their advantages as nontoxic, biocompatible metal sources with outstanding physicochemical features with their raw materials being readily available and inexpensive.[25, 26]

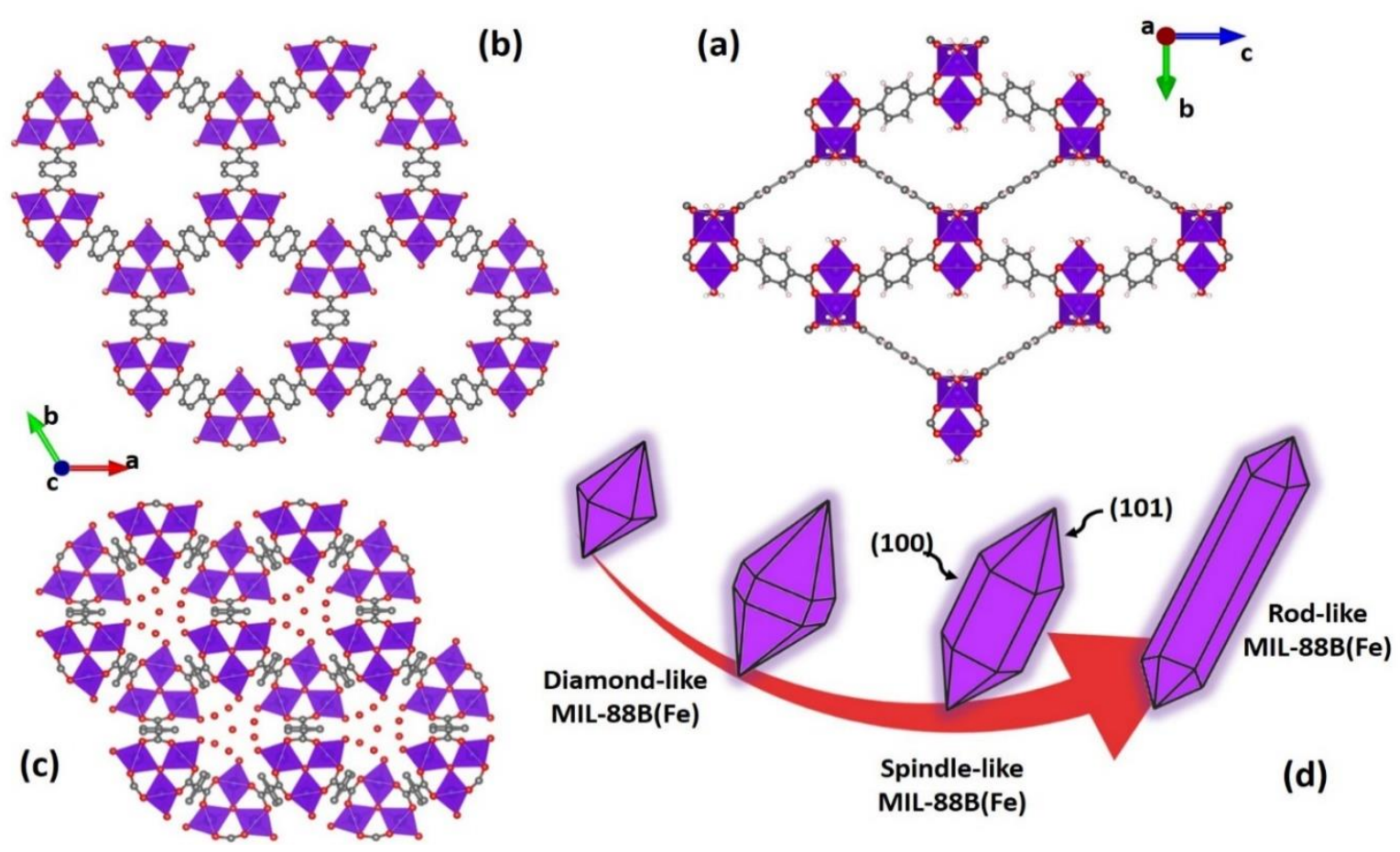

Figure 1. The crystalline structure of the flexible MIL-88B framework. a) the view of the structure along the a-axis. b) along the c-axis. c) breathing effect due to chemical inclusion. d) different crystal shapes resulting from variations in the synthesis parameters.

In highly energetic systems and solid fuel propellants, ammonium perchlorate (AP) is one of the most commonly used oxidizers.[27, 28] AP comprises fuel and oxidizing elements in the same molecule; with high active oxygen content. The decomposition of AP follows an initial endothermic process, whereby a phase transition takes place from the orthorhombic structure to the cubic, which experiences high activation energy.[29,30] At higher temperatures, its crystals become unstable and degrade before melting, similar to other ammonium salts. This degradation is accompanied by a dissociative sublimation and the release of ammonia gas $\left(\mathrm{NH}_{3}\right)$ and perchloric acid $\left(\mathrm{HClO}_{4}\right)$, which accounts for $30 \%$ wt. of the whole decomposition process.[31, 32] 
The combustion of AP has been widely studied; AP decomposition was found to be a complex process. During combustion, its reactive species undergo a sequence of chain reactions with the production of free oxygen and other gaseous products (i.e., $\mathrm{O}_{2}, \mathrm{NO}$, and $\mathrm{NO}_{2}$ ), yielding a high oxidizing power. Generally, combustion reactions are spontaneously propagating exothermic reactions that require specific activation energy to start the reaction. In the case of energetic materials containing AP, the highly endothermic changes of its dissociation and sublimation have high activation energy and hence could result in a low burning rate.[33]

A catalyzed combustion process can decrease the required activation energy and sustain the whole combustion process at a high propagation index.[34] In the case of AP, this catalysis affects the endothermic decomposition of the oxidizer. Transition metal oxides can catalyze AP thermal decomposition, with significant changes in combustion characteristics. [35-38] Ferric oxide is the most active of these catalysts, mainly if used in the nano-scale range.[39, 40] Nanostructured energetic systems can experience smaller critical diameters, high reaction rate, high heat output, as well as high heat release rate.[35, 38, 41]

Here, the iron-based MIL-88B was synthesized following a rapid microwave-assisted solvothermal method. The highly efficient microwave method provided high-quality MIL-88B(Fe) crystals in high yield and excellent phase purity. It represented an energy-saving route for the rapid synthesis of the targeted MOF crystals.[42] In addition, the microwave-assisted technique provided smaller crystals than the conventional method.[43] The MIL-88B(Fe) was characterized with XRD, FTIR, SEM, TEM, TGA, and DSC. It was then integrated into an AP matrix to control the thermal decomposition of the entire matrix. During combustion, the organic linker of the MIL$88 \mathrm{~B}(\mathrm{Fe})$ framework decomposes first with the release of $\mathrm{CO}_{2}$ and $\mathrm{H}_{2} \mathrm{O}$ molecules.[25, 44] The decomposition of MIL-88B(Fe) gives a high content of $\mathrm{Fe}_{2} \mathrm{O}_{3}$ nanoparticles as residuals homogeneously dispersed into the AP matrix resulting in the exclusive formation of monodispersed nano-catalysts.[45-47] It is expected that further combustion of the AP/MIL-88B(Fe) matrix significantly changes the decomposition of AP, yielding a higher burning rate.

\section{Experimental}

All synthetic manipulations were performed under ambient atmosphere unless otherwise stated.

\subsection{Materials}

For the MOF synthesis, Iron(III) chloride hexahydrate $\left(\mathrm{FeCl}_{3} \cdot 6 \mathrm{H}_{2} \mathrm{O}, 97 \%\right), \quad 1,4-$ Benzenedicarboxylic acid "terephthalic acid" $\left(\mathrm{H}_{2} \mathrm{BDC}, 98 \%\right), \mathrm{N}, \mathrm{N}$-dimethyl formamide (anhydrous DMF, 99.8\%), Ethanol (EtOH, 98\%), and Acetone $\left(\mathrm{CH}_{3} \mathrm{COCH}_{3}, 97 \%\right)$ for the nanocomposite were all purchased from Sigma-Aldrich (Canada). In addition, ammonium perchlorate $\left(\mathrm{NH}_{4} \mathrm{ClO}_{4}, 99 \%\right)$ was purchased from AlphaChemica (India). All chemicals were used as received with no further processing. 


\subsection{Synthesis of MIL-88B(Fe)}

The iron-based MIL-88B crystals were synthesized following the reported Metzler-Nolte method with slight modifications, in which the microwave-assisted technique was adopted.[16,17] The synthesis took place in the $30 \mathrm{ml}$-glass vial of Anton Paar's Microwave reactor (Monowave 400). In a typical procedure, as shown in Figure 2, an equimolar mixture of $\mathrm{FeCl}_{3} \cdot 6 \mathrm{H}_{2} \mathrm{O}(0.69 \mathrm{mmol}$, $0.187 \mathrm{~g})$ and $\mathrm{H}_{2} \mathrm{BDC}(0.69 \mathrm{mmol}, 0.115 \mathrm{~g})$ was weighed directly in the reaction vial. Then, $15 \mathrm{ml}$ DMF was added to the mixture, and the solution was magnetically stirred for $30 \mathrm{~min}$ at room temperature to ensure complete dissolution of the components. Later on, the vial was covered with a Teflon-lined silicon septum and placed into the reaction chamber of the microwave reactor. The reaction proceeded after heating the reaction medium to $150{ }^{\circ} \mathrm{C}$ and maintaining the temperature for $10 \mathrm{~min}$ under constant stirring $(500 \mathrm{rpm})$. After the reaction, the reactor chamber was cooled to room temperature by the circulation of air introduced to the instrument under the pressure of 6 bar. (Detailed reaction progress and variation of the parameters during synthesis are reported and plotted in the supporting information (Table S1, Figure S2, and S3)).

The reaction yielded an orange-colored suspension that was centrifuged at a speed of 10,000 rpm for $10 \mathrm{~min}$. The separated solids were washed with DMF $(\times 2)$, ethanol $(\times 3)$ and then dried at 80 ${ }^{\circ} \mathrm{C}$ overnight. The dried powders were kept under vacuum until further use.

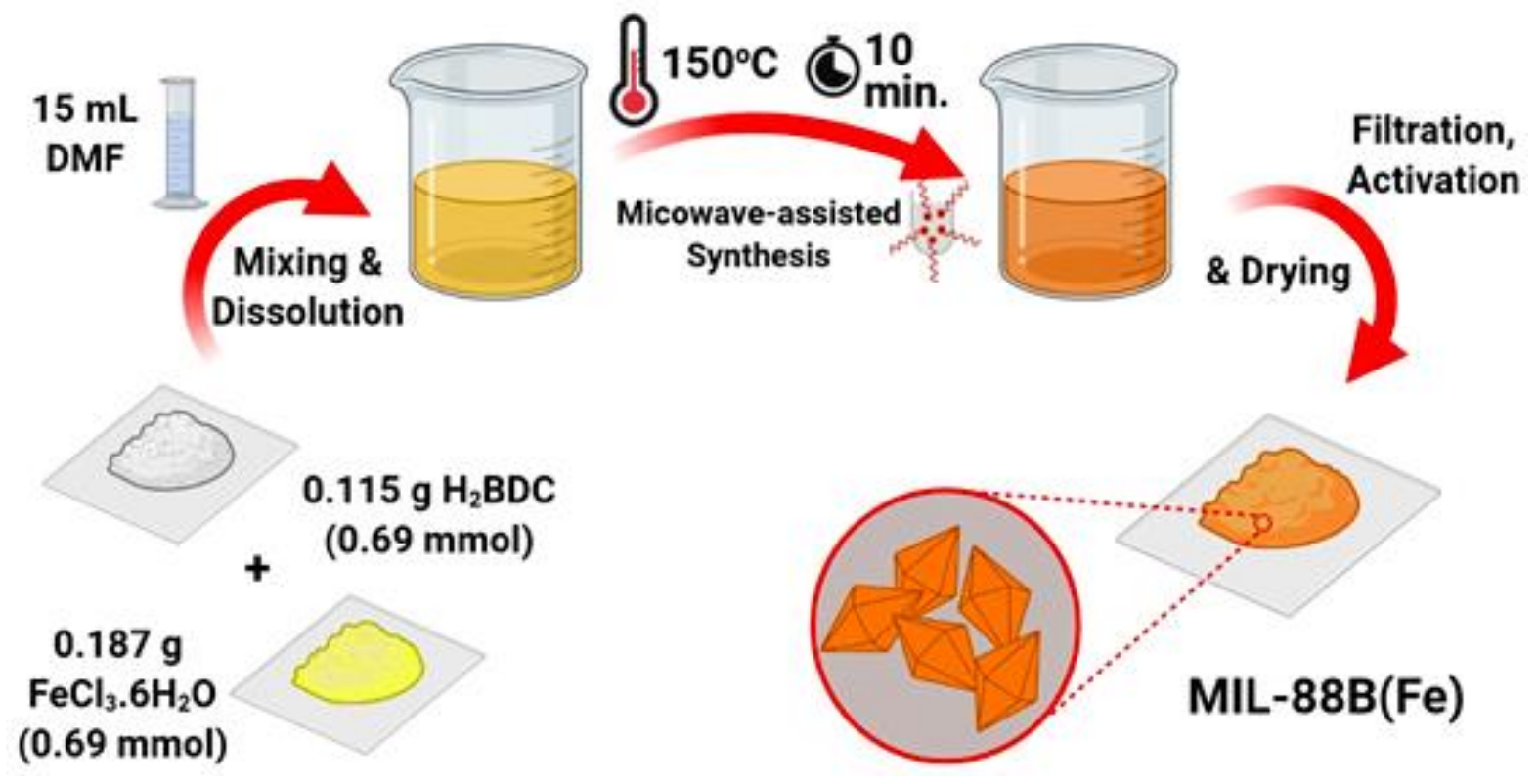

Figure 2. Schematic diagram for the MIL-88B(Fe) synthesis procedures via microwave-assisted technique. 


\subsection{Material Characterization}

Powder X-ray diffraction (PXRD) data were recorded on a Bruker D8 Advance diffractometer equipped with Bragg-Brentano geometry and $\mathrm{Ni}$-filtered $\mathrm{Cu}-\mathrm{K} \alpha$ radiation (wavelength, $\lambda_{\mathrm{K} \alpha}=$ $1.5406 \AA$ ). Samples were prepared by placing a thin layer of the powder directly on a low-zero background silicon wafer supported on the sample holder. The pattern was collected in the $2 \theta$ range of $3^{\circ}-40^{\circ}$ with a step size of $0.02^{\circ}$.

Fourier-transform infrared spectroscopy was applied using the attenuated total reflection (ATR) Perkin Elmer spectrum 65 spectrometer equipped with a diamond crystal. Characterization took place over the wavenumber range of $4000-450 \mathrm{~cm}^{-1}$, with a resolution of $4 \mathrm{~cm}^{-1}$, and an accumulation of 32 scans in absorption mode.

Adsorption isotherms were measured using a Quantachrome autosorb-1 analyzer with $\mathrm{N}_{2}$ as adsorbate at $77 \mathrm{~K}$. Prior to adsorption experiments, outgassing of the samples was performed in vacuo at $250{ }^{\circ} \mathrm{C}$ for $12 \mathrm{~h}$ with a heating ramp of $5{ }^{\circ} \mathrm{C} \mathrm{min}-1$. The specific surface area was determined by applying the Brunauer-Emmett-Teller (BET) equation on the nitrogen adsorptiondesorption isotherms at a relative pressure $\left(\mathrm{P} / \mathrm{P}_{0}\right)$ between 0.05 and 0.15 .

Thermogravimetric analysis (TGA) was performed to establish the thermal stability of the produced MOF on a TGA Q50 instrument by utilizing $5 \mathrm{mg}$ of each sample. Samples were heated at a controlled heating rate of $10{ }^{\circ} \mathrm{C} \mathrm{min}-1$ from ambient temperature to $800{ }^{\circ} \mathrm{C}$ under flowing air. The balance and flow rates were both of $20 \mathrm{~mL} \mathrm{~min}^{-1}$.

Scanning Electron Microscopy (SEM) was used to investigate the crystalline morphology and topology of the MIL-88B MOF. Images were obtained using a Carl Zeiss scanning electron microscope (Model: EVO MA 10, Germany). Samples were suspended in methanol and deposited onto carbon tape. Transmission electron microscopy (TEM, JEOL JEM-2100F) was also employed to record images of the material at $200 \mathrm{kV}$ in bright field imaging mode.

Differential Scanning Calorimetry (DSC) was conducted in closed-pan type experiments via the TA Instruments Q2000 Modulated-DSC $\odot$. Approximately $5 \mathrm{mg}$ of each sample was weighed in airtight-sealed aluminum pans. Samples were then cooled to $0{ }^{\circ} \mathrm{C}$, before heating at a heating rate of $10{ }^{\circ} \mathrm{C} \mathrm{min}-1$ until a temperature of $400{ }^{\circ} \mathrm{C}$. A constant nitrogen purging of $50 \mathrm{~mL} \mathrm{~min}^{-1}$ was maintained during the experiments. The TGA and the DSC data were analyzed using the Universal Analysis software version 2000 from the TA instruments website.

\subsection{Integration of MIL-88B(Fe) MOF into AP matrix}

For the matrix preparation, MIL- $88 \mathrm{~B}(\mathrm{Fe})$ was first dispersed in acetone and then sonicated for 30 minutes using an ultrasonic probe homogenizer (400 W - $24 \mathrm{kHz}, 50 \%$ Amp. , Hielscher Germany). Ammonium perchlorate was dissolved in the acetone colloid, and dichloromethane was 
employed as a proper anti-solvent. Finally, the precipitated particles were filtered and dried at 80 ${ }^{\circ} \mathrm{C}$ for SEM imaging and TGA.

\subsection{Thermal behavior of AP nanocomposite}

The catalytic effect of the synthesized MIL-88B(Fe) and its decomposition residue on AP's thermal decomposition was investigated via DSC. The tested sample was heated to $500{ }^{\circ} \mathrm{C}$ at a controlled heating rate of $10{ }^{\circ} \mathrm{C} \mathrm{min}-1$ under $\mathrm{N}_{2}$ flow of $50 \mathrm{ml} \mathrm{min}^{-1}$. The impact of the MOF structure and iron oxide nanocatalyst on AP's weight loss with temperature elevation was further investigated using TGA.

\section{Kinetic study of AP nanocomposite}

The impact of MIL- $88 \mathrm{~B}(\mathrm{Fe})$ on AP's decomposition rate was evaluated by TGA. The AP nanocomposite sample was heated at a rate of $2,4,6,8$, and $10{ }^{\circ} \mathrm{C} \mathrm{min}{ }^{-1}$. Kissinger and KissingerAkahira-Sunose (KAS) models were employed for kinetic analysis and activation energy calculations.[48, 49]

The Kissinger's model was employed to calculate the activation energy (Ea) of AP nanocomposite (Equation 1).[50, 51]

$$
-\frac{E a}{R}=\frac{d \ln \left(\beta / T_{p}^{2}\right)}{d\left(1 / T_{p}\right)}
$$

where, Ea is the activation energy, $\mathrm{R}$ is the gas constant, $\beta$ is the heating rate. and $\mathrm{Tp}$ is the peak temperature, corresponding to the position of the rate peak maximum. The peak temperature (Tp) is determined as the temperature of the peak signal (maximum or minimum) measured by DSC, DTA or derivative thermogravimetry (DTG).

The Kinetic parameters of Kissinger's model were evaluated using Kissinger-Akahira-Sunose (KAS) model (Equation 2).[52]

$$
\ln \left(\frac{\beta_{\mathrm{i}}}{\mathrm{T}_{\alpha, \mathrm{i}}^{1.92}}\right)=\text { Const }-1.0008 \frac{\mathrm{E} \alpha}{\mathrm{RT} \alpha}
$$




\section{Results and Discussion}

\subsection{Characterization of MIL-88B(Fe) MOF}

\subsubsection{Powder X-ray Diffraction (PXRD):}

According to the microwave-assisted method of Metzler-Nolte, heating a solution of $\mathrm{Fe}^{3+}$ and $\mathrm{H}_{2} \mathrm{BDC}$ in DMF with a molar ratio of $1: 1: 140$ at $150^{\circ} \mathrm{C}$ for 10 min would result in a MIL-88B(Fe) structure with diamond-like and short spindle-like crystals.[16] Characterization via PXRD confirmed the achievement of the MIL- $88 \mathrm{~B}(\mathrm{Fe})$ framework by the adopted synthesis method. The resulting pattern (Figure 3, "Blue") showed a nearly flat background, and high-intensity peaks were recognized in the $2 \theta$ range of $5^{\circ}-30^{\circ}$. $[16,17]$ The experimental pattern agreed with the calculated one (Figure 3, "Red"), revealing that the [101] plane is the dominant one while the [100] plane is the least intense. $[16,18,19]$

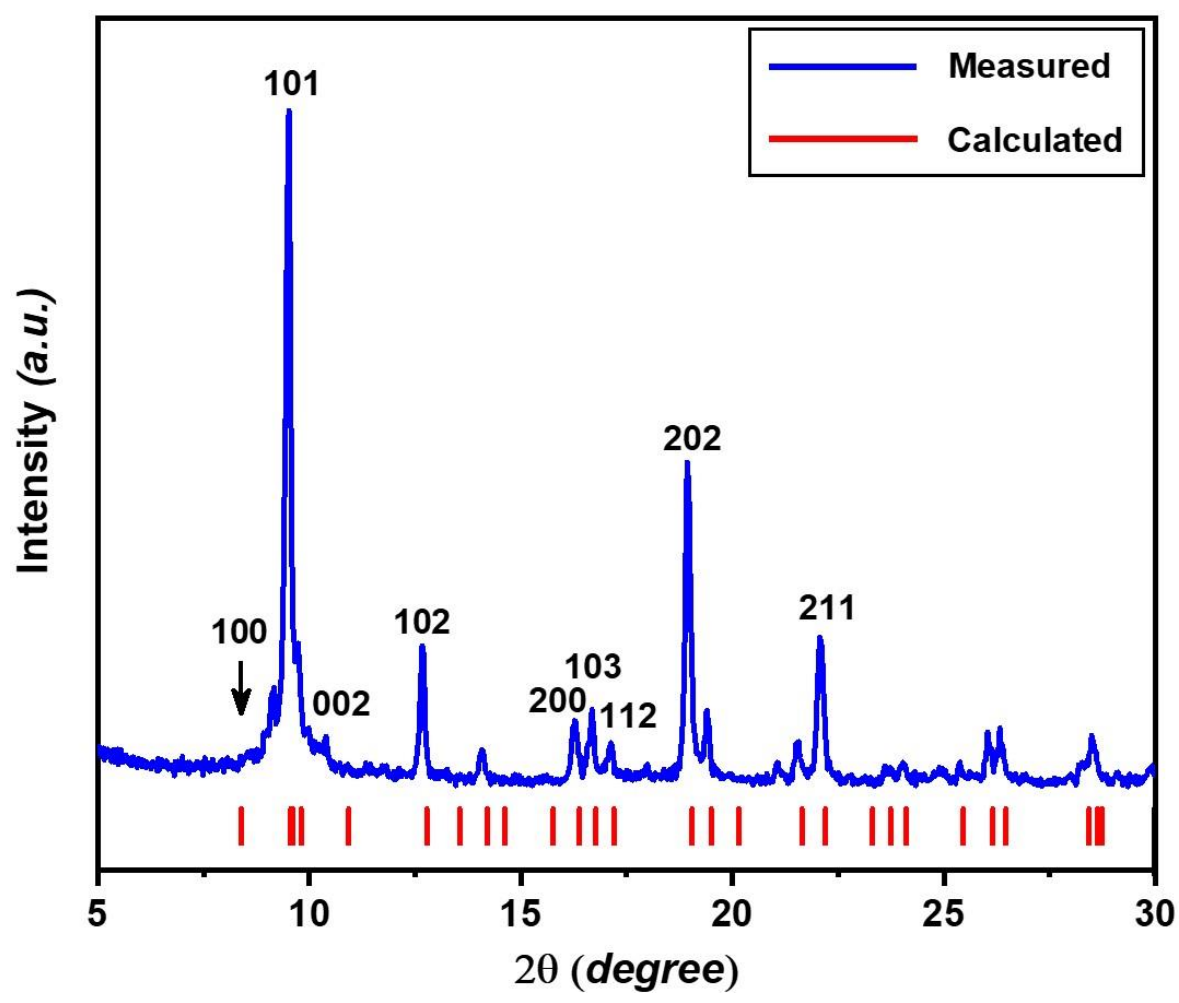

Figure 3. The XRD pattern for the microwave-synthesized MIL-88B $(\mathrm{Fe})$ metal-organic framework compared to the calculated peaks of the simulated structure. (The original simulation file was obtained from Cambridge Crystallographic Data Centre "CCDC" under the identifier name of "YEDKOI") 


\subsubsection{Scanning Electron Microscopy (SEM):}

Scanning electron microscopy (SEM) confirmed the findings of PXRD, whereby the hexagonal bipyramidal-shaped (diamond-like) crystals of MIL-88B $(\mathrm{Fe})$ were the major type of crystals produced (Figure 4). Furthermore, the images demonstrated the uniform crystal size in the range of a few microns (1-2 micron) with a preferential growth of the 101 facets rather than that of the 100 ones.[16,19] The presence of smaller crystals of the same shape could also be detected. (Supporting information, Figure S2).
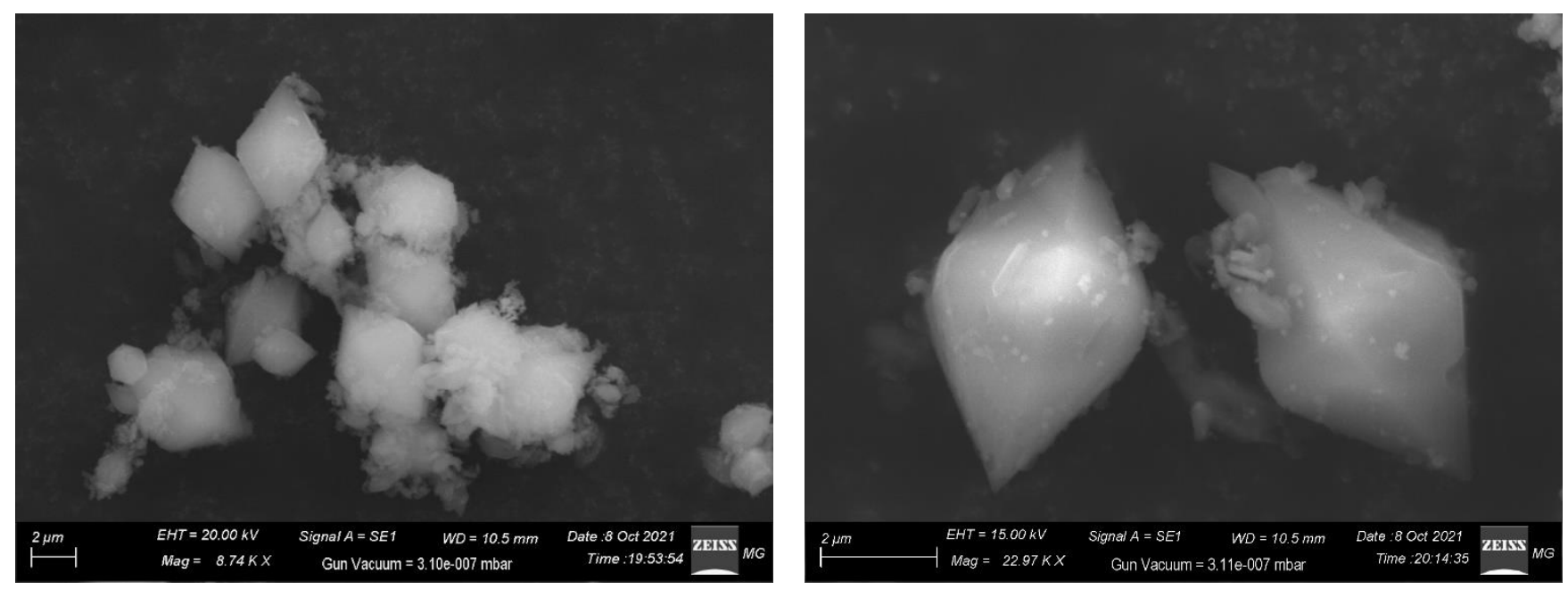

Figure 4. SEM micrographs of the as-synthesized MIL88-B(Fe) hexagonal bipyramidal-shaped crystals.

Elemental mapping was conducted using the EDAX detector of the SEM to assess the dispersion of the main elements within the framework (Figure 5). As explained above, in the MIL-88B(Fe) framework structure, each metal trimer comprises three metal ions connected through central oxygen and six linker molecules. Besides, at the outer vertices of the trimer, either a water molecule or a hydroxyl group is attached to the metal ion, satisfying its coordination. The negative hydroxyl ions are sometimes replaced by chloride ions provided by the initial precursors. Hence, detecting most of these elements in the mapping was reasonable, including $\mathrm{Fe}, \mathrm{O}, \mathrm{C}$, and $\mathrm{Cl}$ (Figure 5). The mapping confirmed the uniform elemental dispersion within the sample. Moreover, the obtained elemental composition confirmed the chemical formula of the MIL-88B MOF $\left(\mathrm{C}_{24} \mathrm{H}_{12} \mathrm{O}_{13} \mathrm{Fe}_{3} \mathrm{Cl}\right)$ with respect to the atomic and mass percentages indicated (Figure 6). 


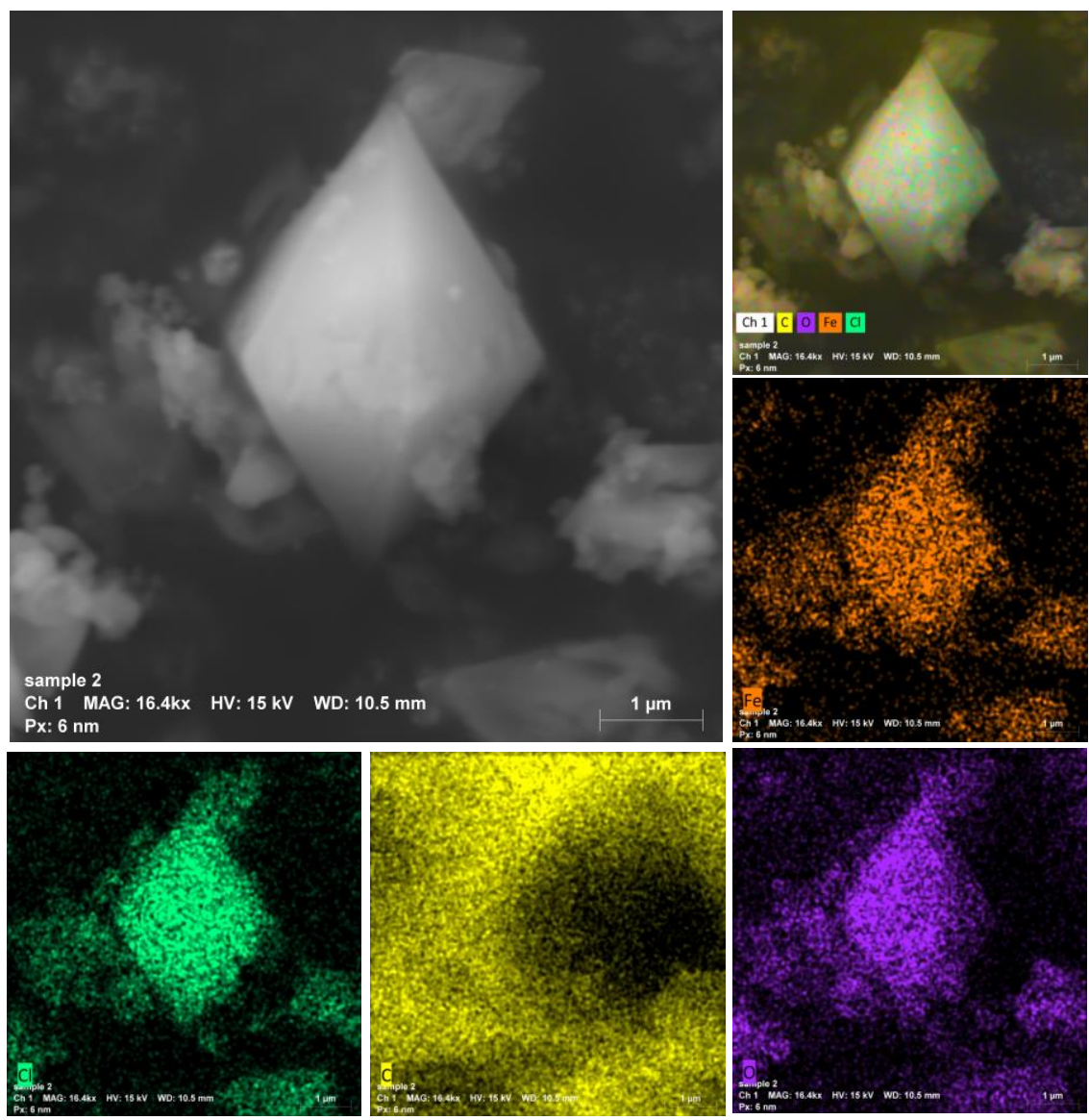

Figure 5. Elemental mapping of the as-synthesized MIL88-B (Fe) MOF.

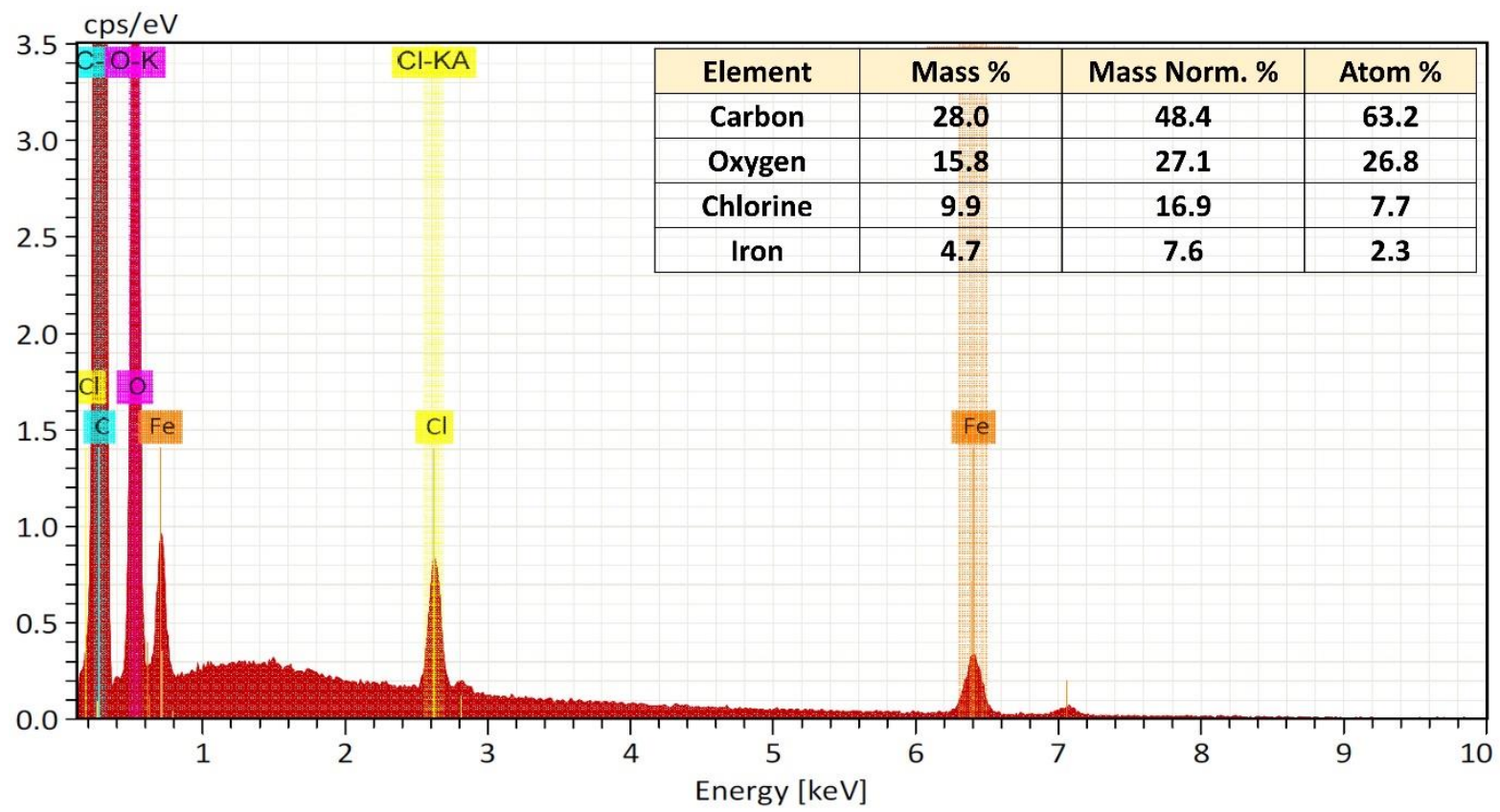

Figure 6. Elemental composition of the MIL88-B (Fe) framework. 


\subsubsection{Transmission Electron Microscopy (TEM):}

As reported above, the SEM images showed that the majority of the crystals produced have a diamond-like shape and a particle size of a few microns. Nevertheless, the TEM micrographs (Figure 7) allowed establishing the existence of smaller particles with an aspect ratio (length/width) around two. These particles are of spindle-like shapes with $400 \mathrm{~nm}$ in length and $200 \mathrm{~nm}$ in width (Figure 7). The reaction medium was heated uniformly under constant microwave power of $300 \mathrm{~W}$ in the original recipe.[16] In the present work, a higher heating rate was applied under an initial high-power pulse reaching a maximum of $850 \mathrm{~W}$ (supporting information, Figure S2). The fast-heating rate applied would result in a higher nucleation rate. This could yield changes in the morphology of the produced crystals depending on the precursors' concentrations at this reaction location. Secondly, no sudden cooling (quenching) was employed at the end of the reaction, as reported in Ref. [16]. On the contrary, in our case, a slow cooling followed (supporting information, Figure S3), which would force the reaction to proceed at a lower temperature. This would favor the growth of already formed crystals and the formation of smaller ones of different (deformed) shapes.
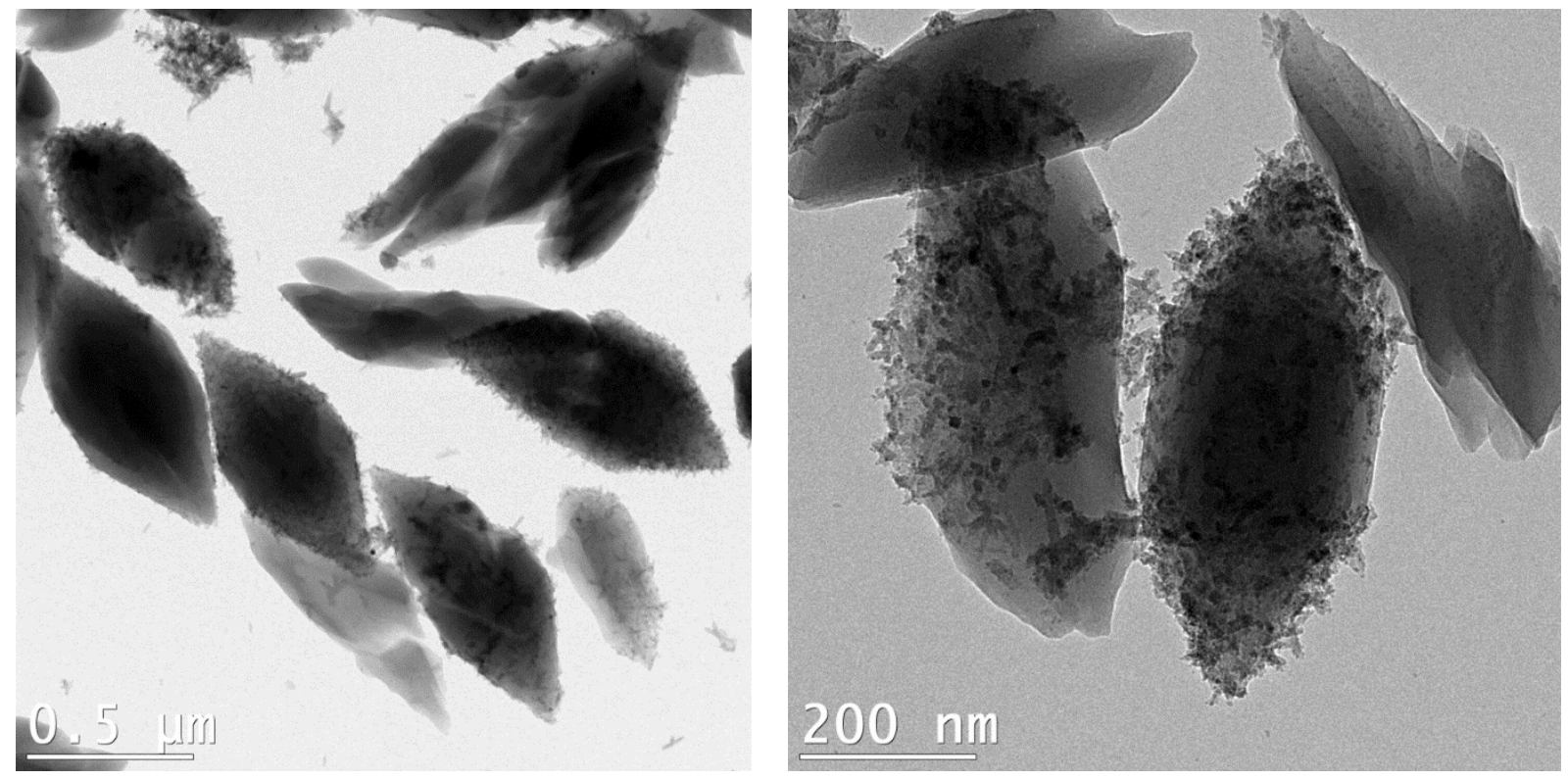

Figure 7. TEM micrographs of MIL- $88 \mathrm{~B}(\mathrm{Fe})$ express the presence of some short spindle-like crystals.

\subsubsection{Fourier-Transform Infrared spectroscopy (FTIR):}

FTIR confirmed the formation of the desired MOF structure (Figure 8) and the connection of the trivalent $\mathrm{Fe}^{3+}$ ions to the ditopic $\mathrm{H}_{2} \mathrm{BDC}$ linker. Indeed, the vibrational spectrum of the obtained crystals agreed with that of Fe-BDC metal-organic frameworks (i.e., MIL-53 and MIL-101), with the high-intensity peaks in the range of $2000-400 \mathrm{~cm}^{-1}$.[53-56] First, the range from 1750-1250 
$\mathrm{cm}^{-1}$ corresponds mainly to the vibrations of the carboxylate group bonds and, to some extent, the aromatic ring. The second region in the range between $1250-600 \mathrm{~cm}^{-1}$ is ascribed to the $\mathrm{C}-\mathrm{H}$ bonds of the ring. Finally, in the region below $600 \mathrm{~cm}^{-1}$, the metal-O bonds' vibrations are detected.

In the first region, the absorption bands around $1631 \mathrm{~cm}^{-1}$ and $1398 \mathrm{~cm}^{-1}$ are assigned to the antisymmetric and symmetric stretching of the dicarboxylate groups, respectively. [56, 57] The peak related to the aromatic ring $(\mathrm{C}=\mathrm{C})$ bonds stretching is recognized at $1507 \mathrm{~cm}^{-1} .[53,54,58]$ In the second region, the peaks at $1017 \mathrm{~cm}^{-1}, 744 \mathrm{~cm}^{-1}, 1166 \mathrm{~cm}^{-1}$, and $883 \mathrm{~cm}^{-1}$ are attributed to the in-plane/out-of-plane bending of the $(\mathrm{C}-\mathrm{H})$ bonds. [53, 54, 56, 58] Most importantly, the absorption of Fe-O bonds could be recognized around $545 \mathrm{~cm}^{-1} .[54,59,60]$

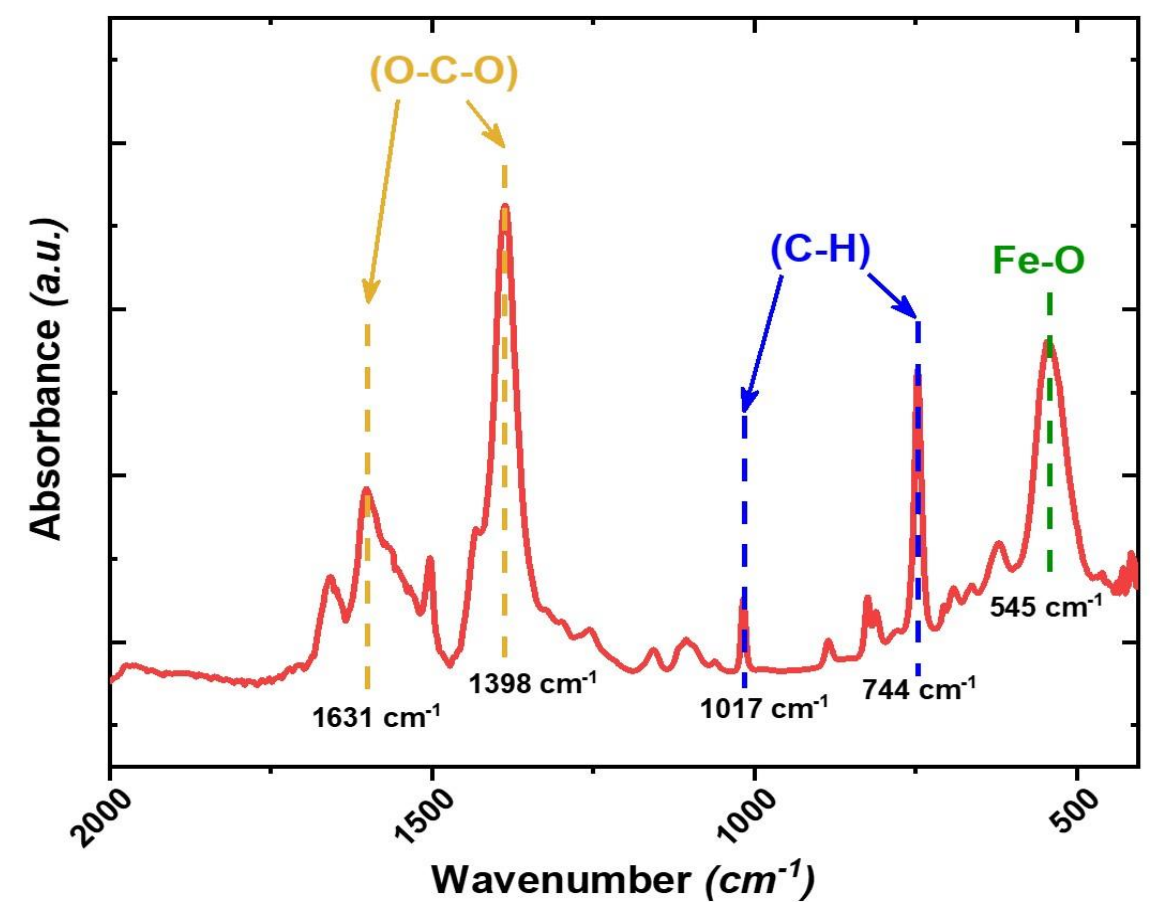

Figure 8. FTIR absorption spectrum of the activated MIL- $88 \mathrm{~B}(\mathrm{Fe})$.

\subsubsection{Surface area measurement:}

The textural properties of the synthesized MIL- $88 \mathrm{~B}(\mathrm{Fe})$ were established using $\mathrm{N}_{2}$ sorption over a relative pressure $\left(\mathrm{P} / \mathrm{P}_{\mathrm{o}}\right)$ range between 0.01 and 0.99 . According to simulations, the $3 \mathrm{D}$ structure of the MIL-88B framework at its maximum expansion should exhibit a high surface area of 3040 $\mathrm{m}^{2} \mathrm{~g}^{-1}$.[61] However, due to the high flexing character of its structure and its low affinity towards the adsorption of nitrogen gas, a low specific surface area was measured.[61,62] The experimental $\mathrm{N}_{2}$ adsorption-desorption curve is shown in Figure 9, showing the type-I isotherm, usually obtained for microporous solids. 


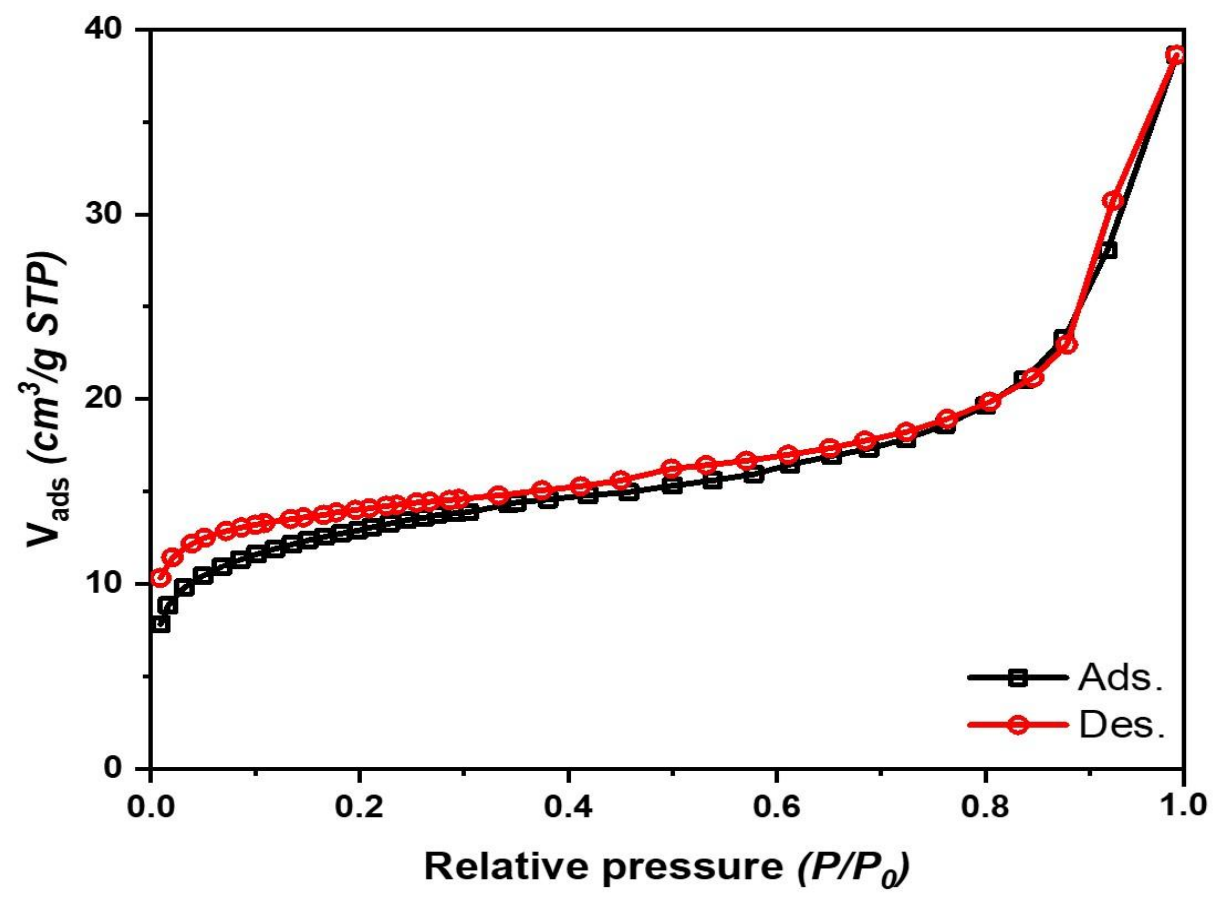

Figure 9. Adsorption/desorption isotherm of the MIL-88B(Fe) MOF.

For MOFs, the BET analysis is commonly used for determining surface areas from nitrogen adsorption isotherms.[63] It was originally derived for multilayer gas adsorption onto flat surfaces. However, in the case of metal-organic frameworks, gas adsorption usually takes place through pore-filling instead of layer formation. [64] Nevertheless, It is reported that the BET method is still applicable in the case of microporous structures at a low-pressure range, whereby a linear fitting of the BET plot is achieved with a positive y-intercept.[63-65] Within this range, the measured surface area usually agrees with the accessible surface area calculated through simulations.

Hence, the specific surface area of the obtained MIL- 88 crystals was calculated using the BET method at a relative pressure between 0.05 and 0.15 [63], expressing a specific surface area of 47 $\mathrm{m}^{2} \mathrm{~g}^{-1}$. The fitting for the data obtained within this range matched perfectly with the BET plot (Figure S4). A hysteresis loop was observed on the desorption curve associated with the known breathing effect of the MIL- 88 framework. The pore volume and the pore size would vary due to the swelling and the shrinkage of the pores at different stages. Nevertheless, the low SSA reported for the MIL-88B framework has been highly dependent on the residual adsorbed solvent. [15, 6670] It is discussed in terms of the low affinity of the structure towards the adsorption of nitrogen besides the steric hindrance of the terminal ligands. [66, 67, 71] In addition, due to the flexing character of the MIL-88 structure, degassing the adsorbed solvent from the pores at high temperature would transform the framework from the narrow-pore (np) structure to the closedpore (cp) structure, resulting in a low-measured SSA. 


\subsubsection{Thermal gravimetric analysis (TGA):}

The thermogravimetric profile of the as-produced MIL- $88 \mathrm{~B}(\mathrm{Fe}) \mathrm{MOF}$ was investigated. Samples were subjected to an airflow of $20 \mathrm{ml} \mathrm{min}^{-1}$ with a constant temperature ramp of $10^{\circ} \mathrm{C} \mathrm{min}^{-1}$ from room temperature up to $800^{\circ} \mathrm{C}$. The obtained thermogravimetric curve is presented in Figure 10, demonstrating the structure's high thermal stability.
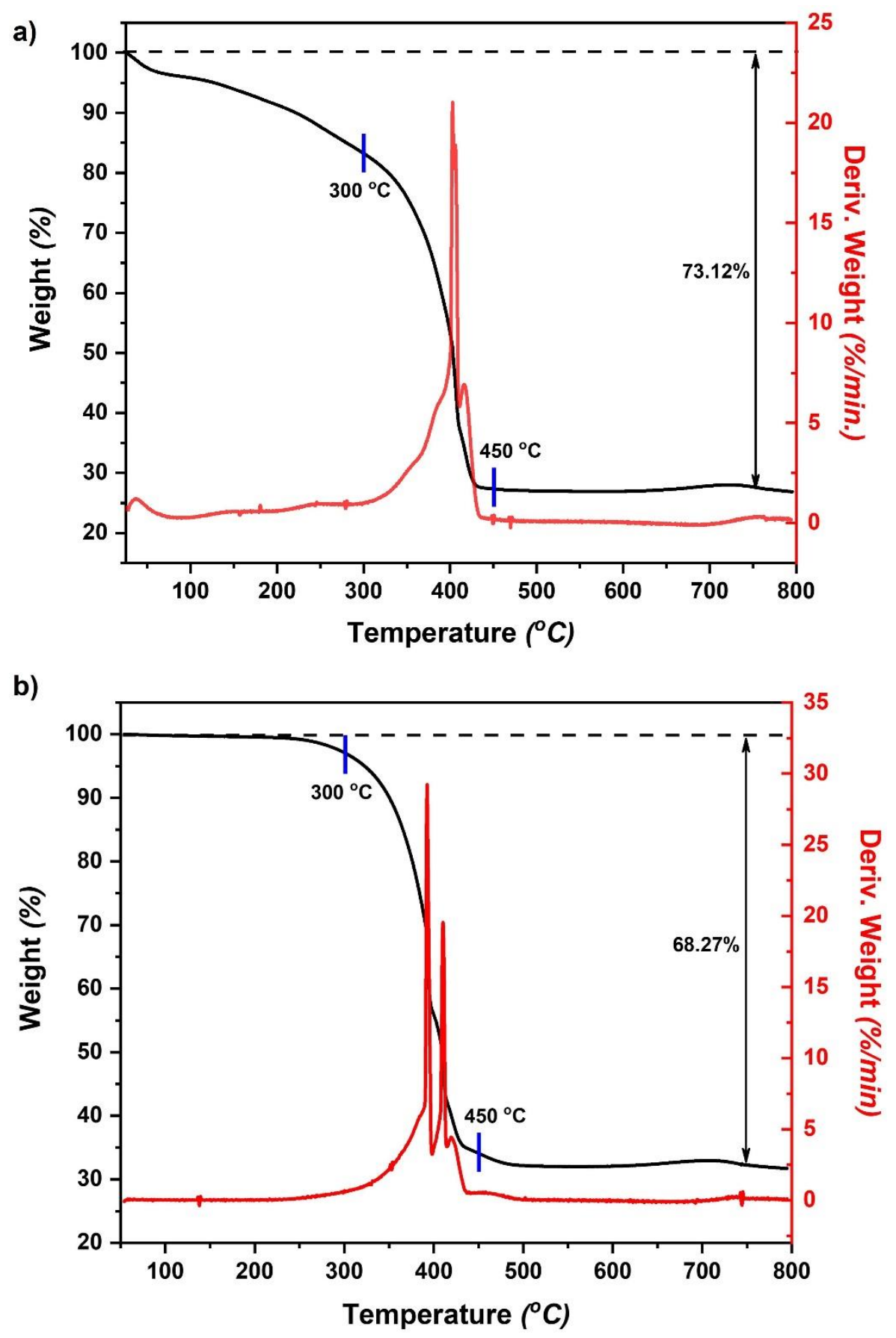

Figure 10. TGA thermograms of the DMF-treated MIL-88B(Fe) MOF a) as-synthesized, b) after thermal treatment at $170{ }^{\circ} \mathrm{C}$ for $3 \mathrm{~h}$. 
The TGA curve of the as-synthesized MOF showed a continuous weight loss as the temperature went up to $500{ }^{\circ} \mathrm{C}$, in which one main step was observed around $400{ }^{\circ} \mathrm{C}$ as indicated by the DTG thermogram (Figure. 10-a). According to previous studies in the literature, such a weight-loss step is related to the thermal decomposition of the MOF structure. On the other hand, the continuous weight loss occurring below $300^{\circ} \mathrm{C}$ is mostly related to the desorption and evaporation of the guest solvents (EtOH and DMF) within the pores adsorbed during synthesis and activation steps. In order to confirm these results, a small amount of the as-synthesized MOF was thermally treated at 170 ${ }^{\circ} \mathrm{C}$ for $3 \mathrm{~h}$ before the TGA analysis (Figure 10-b). The curve of the thermally treated sample showed almost no weight loss (plateau) in the region below $300{ }^{\circ} \mathrm{C}$, followed by a significant weight loss step (equivalent to ca. $68 \%$ ) in the next temperature range between $300{ }^{\circ} \mathrm{C}-450{ }^{\circ} \mathrm{C}$. In this range, the detachment of the BDC linker and decomposition of the whole framework takes place, displaying the high thermal stability of MIL-88B(Fe). In the region above $500{ }^{\circ} \mathrm{C}$, no significant weight loss was witnessed with residual solids of an ochre-red color remaining after decomposition.

As planned, the thermal decomposition of the MIL- $88 \mathrm{~B}(\mathrm{Fe})$ crystals would end up giving smaller particles of $\alpha-\mathrm{Fe}_{2} \mathrm{O}_{3}$ in the nano-range size that would eventually interact with the AP matrix to catalyze its decomposition. The XRD pattern for the TGA test residuals was measured (Figure 11), validating the formation of the $\alpha-\mathrm{Fe}_{2} \mathrm{O}_{3}$ with its recognizable diffraction peaks at $2 \theta=24.1^{\circ}, 33.2^{\circ}$, $35.6^{\circ}, 49.4^{\circ}, 54.0^{\circ}, 62.5^{\circ}$, and $63.9^{\circ}$. Hence, the targeted in-situ sequential formation of the nanostructured oxide particles would be achieved during thermal decomposition during the AP combustion process.

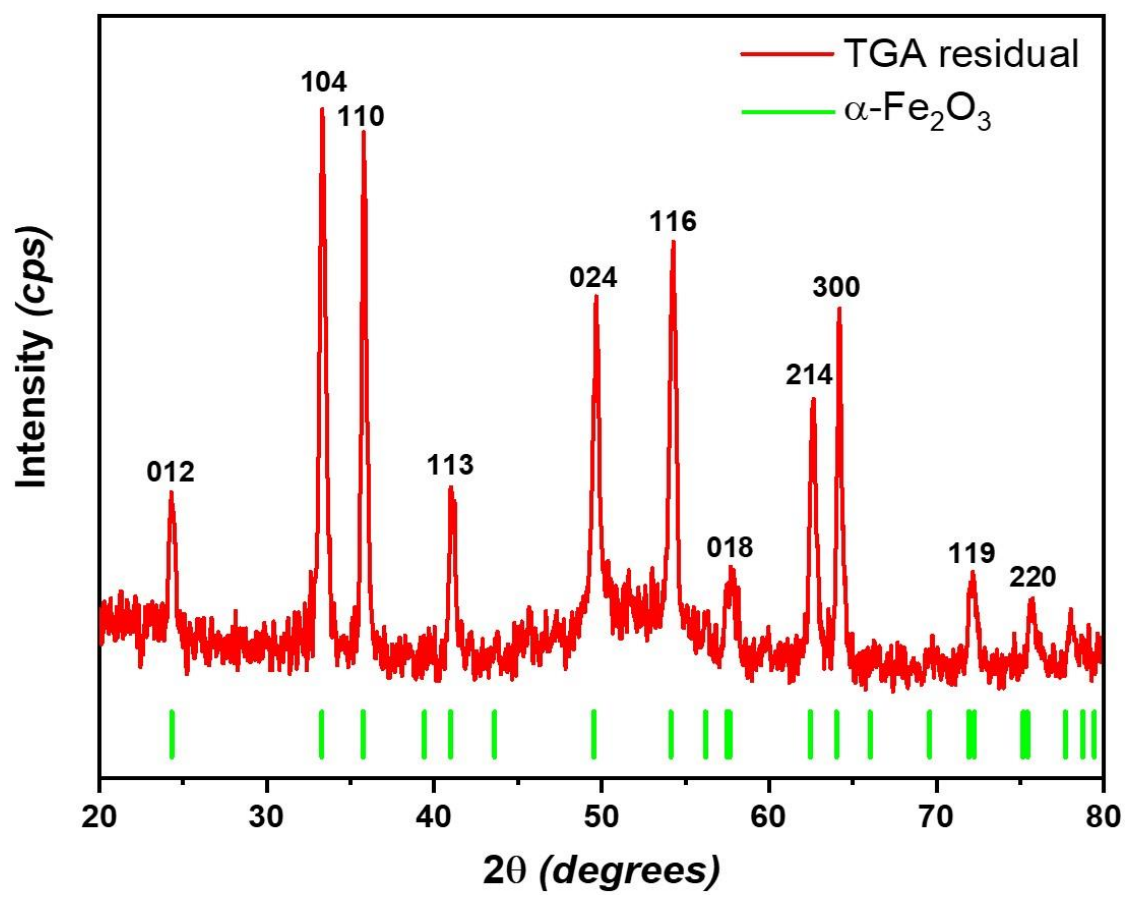

Figure 11. The XRD pattern for the TGA residuals confirms the formation of the $\alpha-\mathrm{Fe}_{2} \mathrm{O}_{3}$ particles as a final product after the calcination of the MIL- $88 \mathrm{~B}(\mathrm{Fe})$ framework. 


\subsection{Characterization of MIL-88B(Fe)/Ammonium perchlorate(AP) nanocomposite}

As shown in Figure 12, introducing the small MIL88 particles into an AP composite resulted in a significant dispersion of AP, with the composite particle size ranging around $3 \mu \mathrm{m}$ compared to the $150 \mu \mathrm{m}$ size of the initial AP particles.
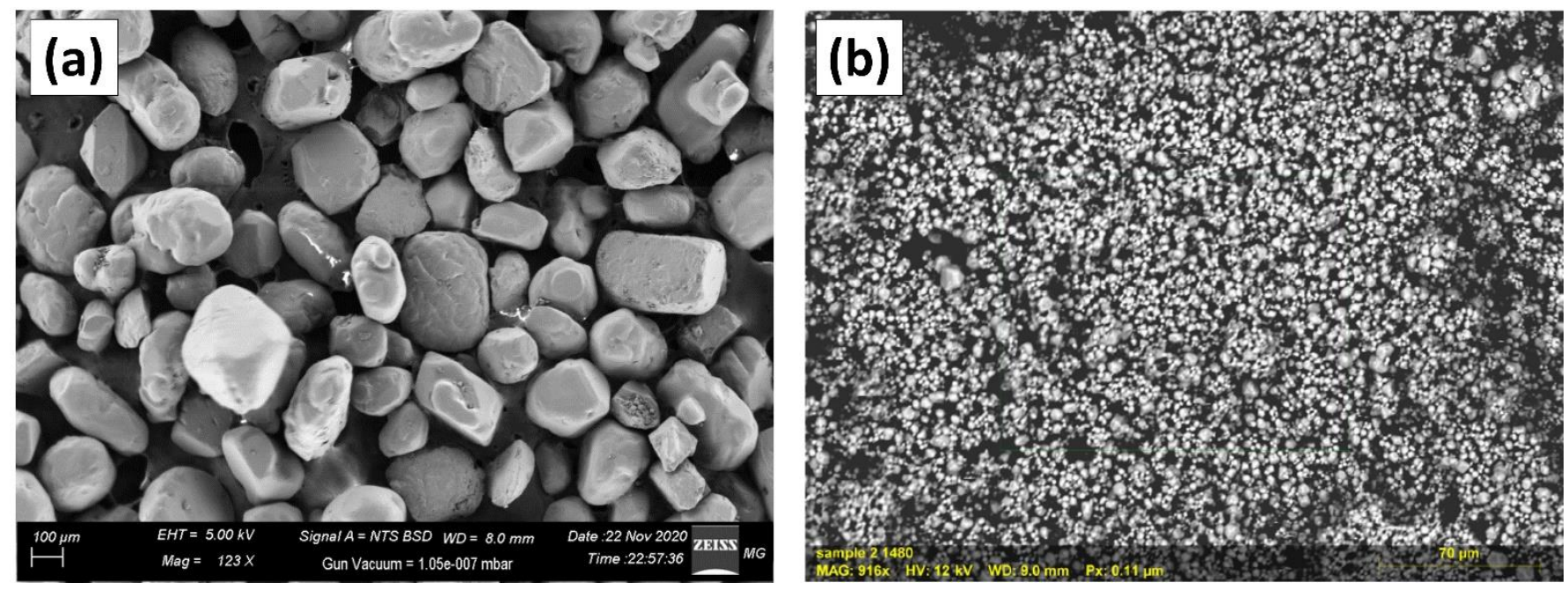

Figure 12. SEM micrographs of pure AP(a), MIL-88B(Fe)/AP nanocomposite (b).

Visual inspection of the MIL-88B(Fe) MOF/AP nanocomposite demonstrated uniform dispersion of MIL-88B(Fe) MOF particles into the oxidizer matrix. Initially, AP demonstrated a white color, whereas the MOF/ AP nanocomposite acquired an orange color at only 1\% wt. added MOF(Figure $13)$.
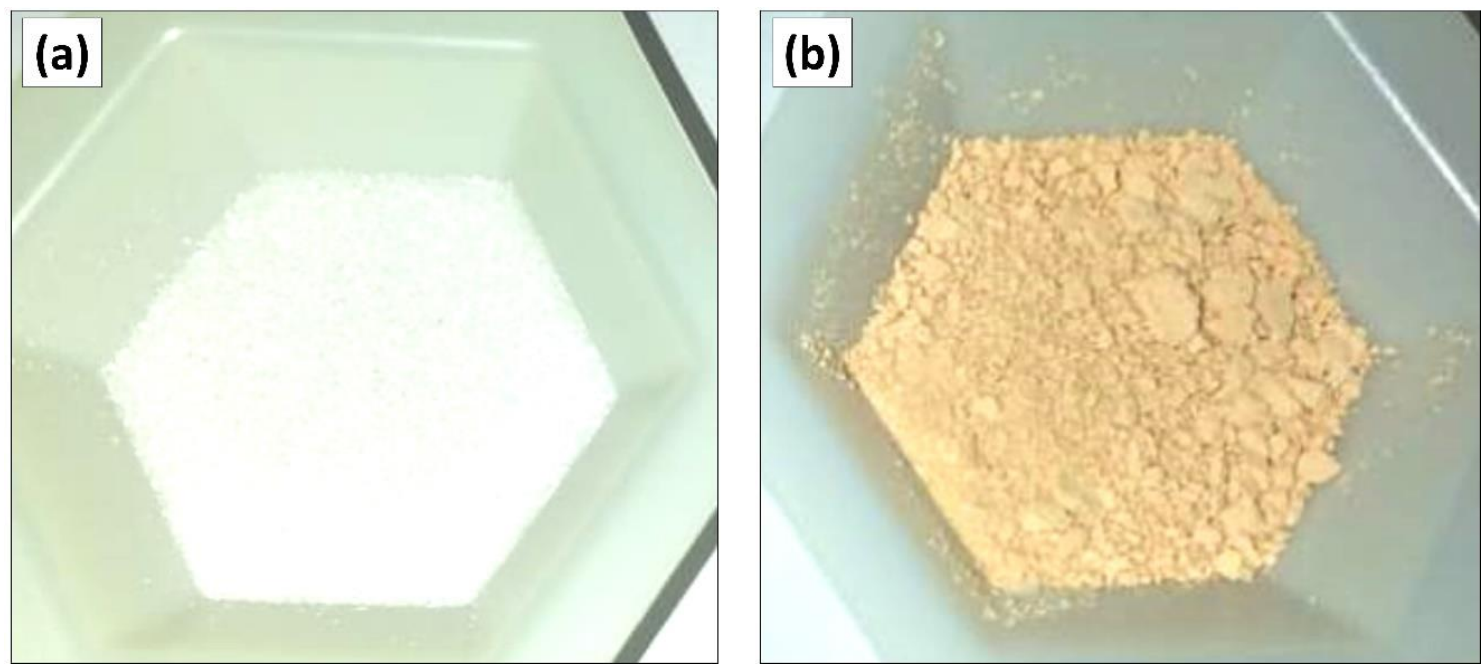

Figure 13. The appearance of pure AP particles (a), MIL-88B(Fe) MOF/AP nanocomposite (b). 
The dispersion of MIL- $88 \mathrm{~B}(\mathrm{Fe}) \mathrm{MOF}$ into the energetic matrix was further investigated via elemental mapping using an EDX detector. Satisfactory uniform elemental dispersion was verified from the EDX micrographs (Figure 14).
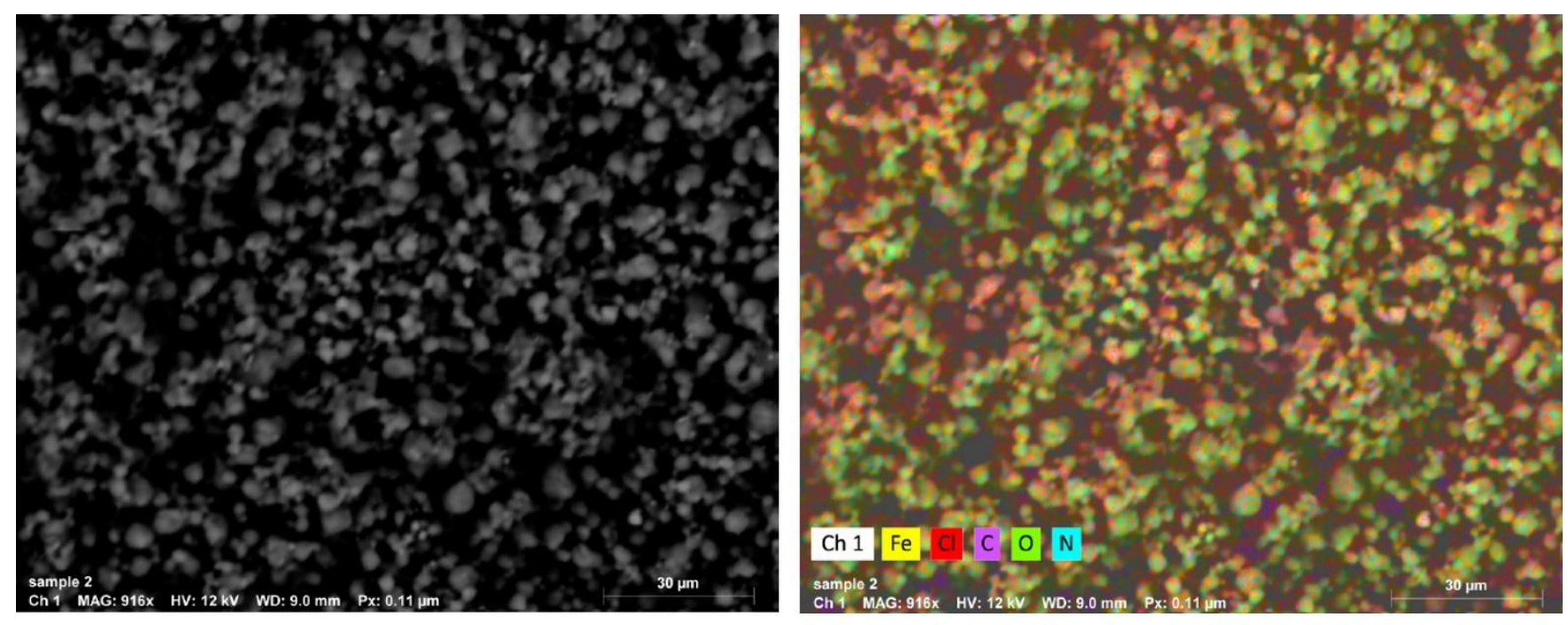

Figure 14. Elemental mapping of MIL-88B(Fe) MOF/AP nanocomposite. 


\subsection{Thermal behavior of MIL-88B(Fe) MOF/AP nanocomposite}

The catalytic efficiency of MIL-88B(Fe) MOF on AP thermal behavior was investigated using DSC. While AP demonstrated a total heat release of $733 \mathrm{~J} \mathrm{~g}^{-1}$, the AP/MOF composite resulted in a $66 \%$ enhanced heat output of $1218 \mathrm{~J} \mathrm{~g}^{-1}$, and the main exothermic decomposition temperature was decreased by $71^{\circ} \mathrm{C}$ (Figure 15).

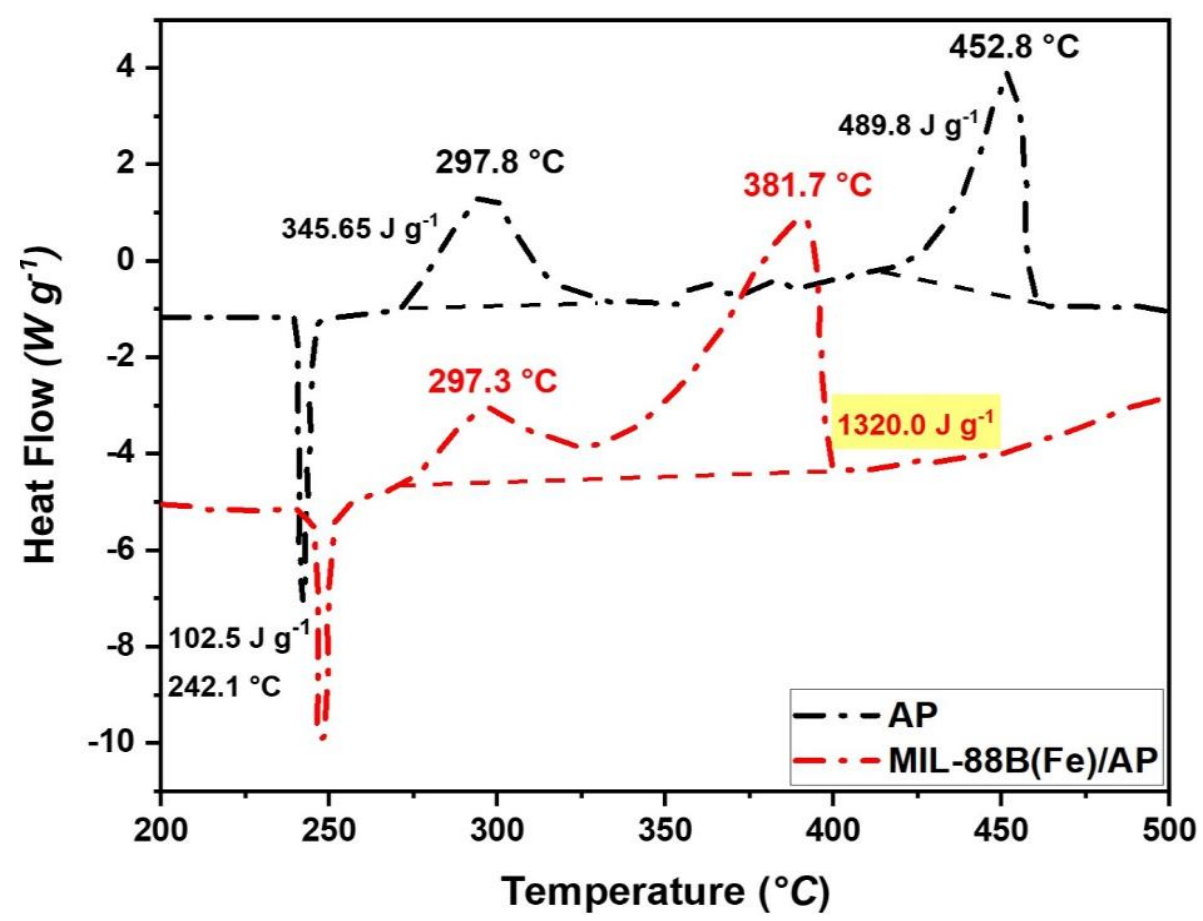

Figure 15. Impact of Mil-88B(Fe)MOF on AP thermal behavior using DSC.

The MIL- $88 \mathrm{~B}(\mathrm{Fe})$ MOF $\left(\mathrm{C}_{24} \mathrm{H}_{12} \mathrm{O}_{13} \mathrm{Fe}_{3} \mathrm{Cl}\right)$ contributed to the AP/MOF composite decomposition through the organic linker decomposition, resulting in higher heat output. Besides, it exhibits a catalytic effect via the $\mathrm{Fe}$ content and boosts the combustion enthalpy thanks to the $\mathrm{O}_{2}$ content. MIL-88B(Fe) exhibited an $\mathrm{O}_{2}$ and $\mathrm{Fe}$ content of $29 \%$ and $24 \%$, respectively; therefore, it resulted in a high catalytic activity with improved interfacial surface area and reactivity. Furthermore, the exclusive evolution of a $\mathrm{Fe}_{2} \mathrm{O}_{3}$ nanocatalyst during the decomposition process supports this catalytic ability, facilitating the decomposition of more AP present in the sample and yielding an enhanced decomposition enthalpy of the composite by $66 \%$. The impact of MIL-88B(Fe) MOF NPs on AP thermal behavior was further evaluated using TGA (Figure 16). 

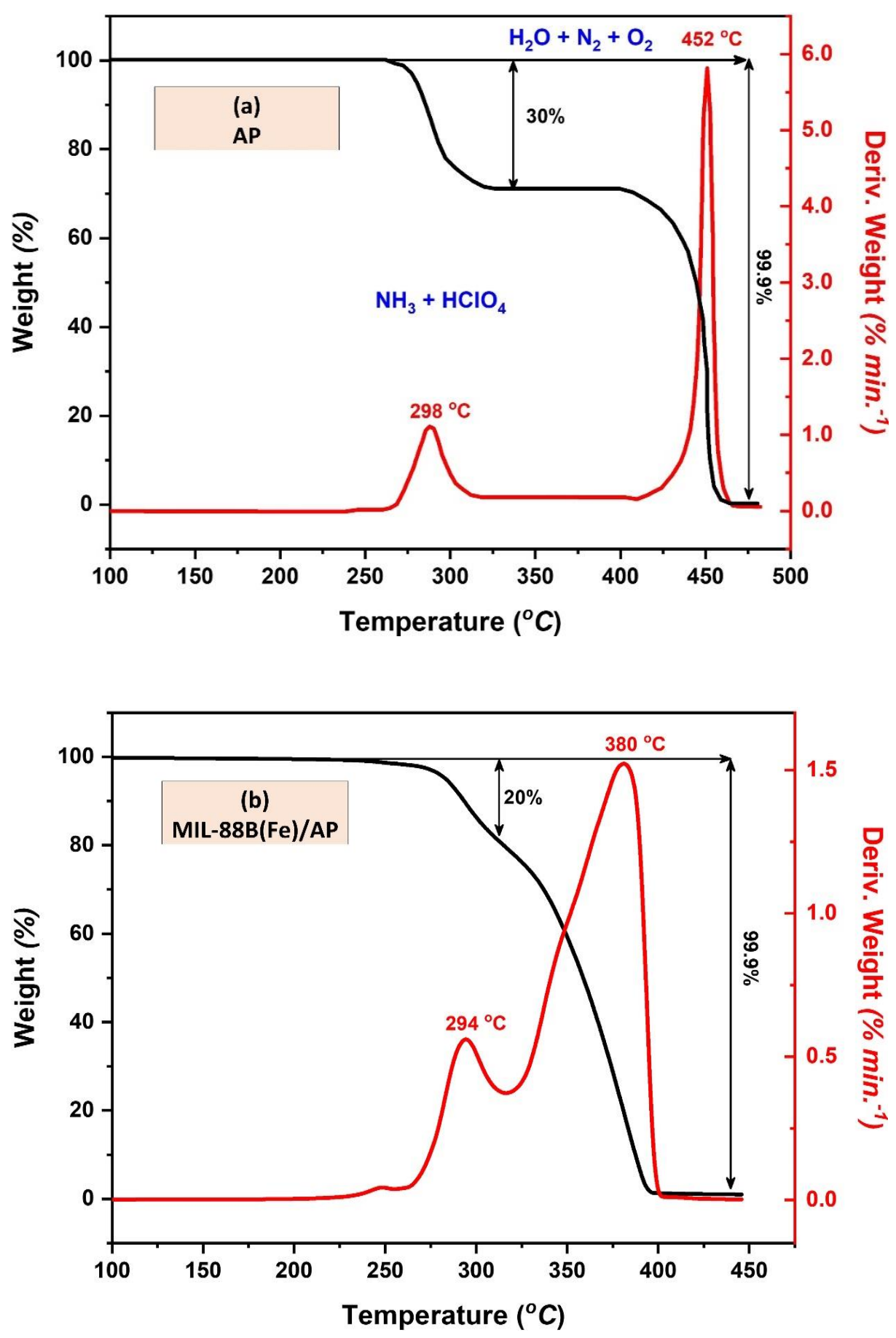

Figure 16. Impact of MIL-88B(Fe) MOF on AP thermal behavior using TGA.

TGA results demonstrated a decrease in AP main decomposition temperature by $72{ }^{\circ} \mathrm{C}$; this result agreed with the DSC outcomes. 


\subsection{Kinetic study of MIL-88B(Fe) MOF/AP nanocomposite}

\subsubsection{Kinetic parameters obtained by the Kissinger method}

Kissinger's model is based on the highest decomposition peak temperature; this temperature was obtained from the DTG thermogram (Figure 17).
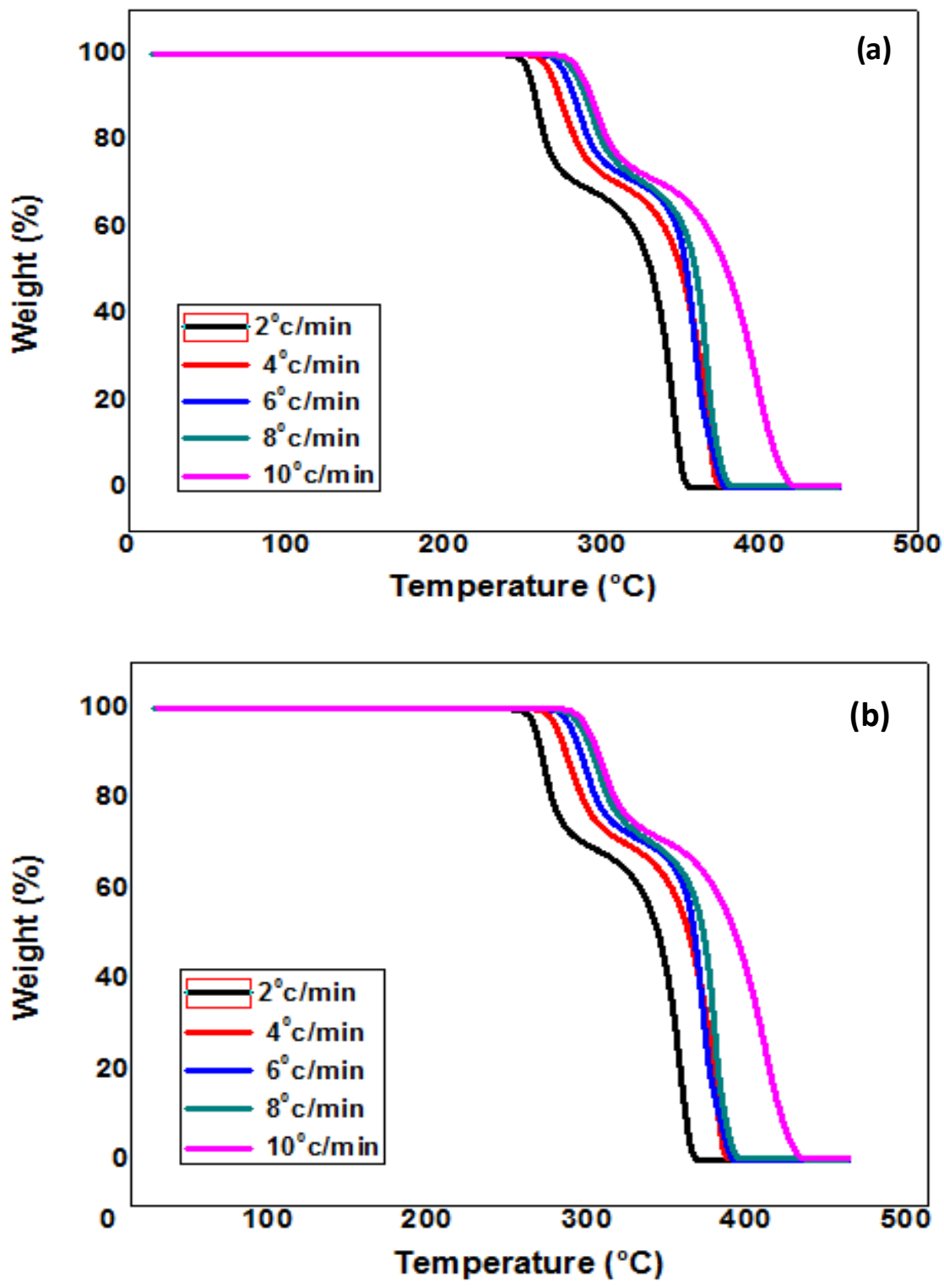

Figure 17. TGA thermogram of AP(a), MIL-88B(Fe)/AP(b).

The activation energy was obtained from the slope of the straight-line $\ln \left(\beta / \mathrm{T}^{2}\right)$ versus $1 / \mathrm{T}$ at the five selected heating rates (Figure 18). 

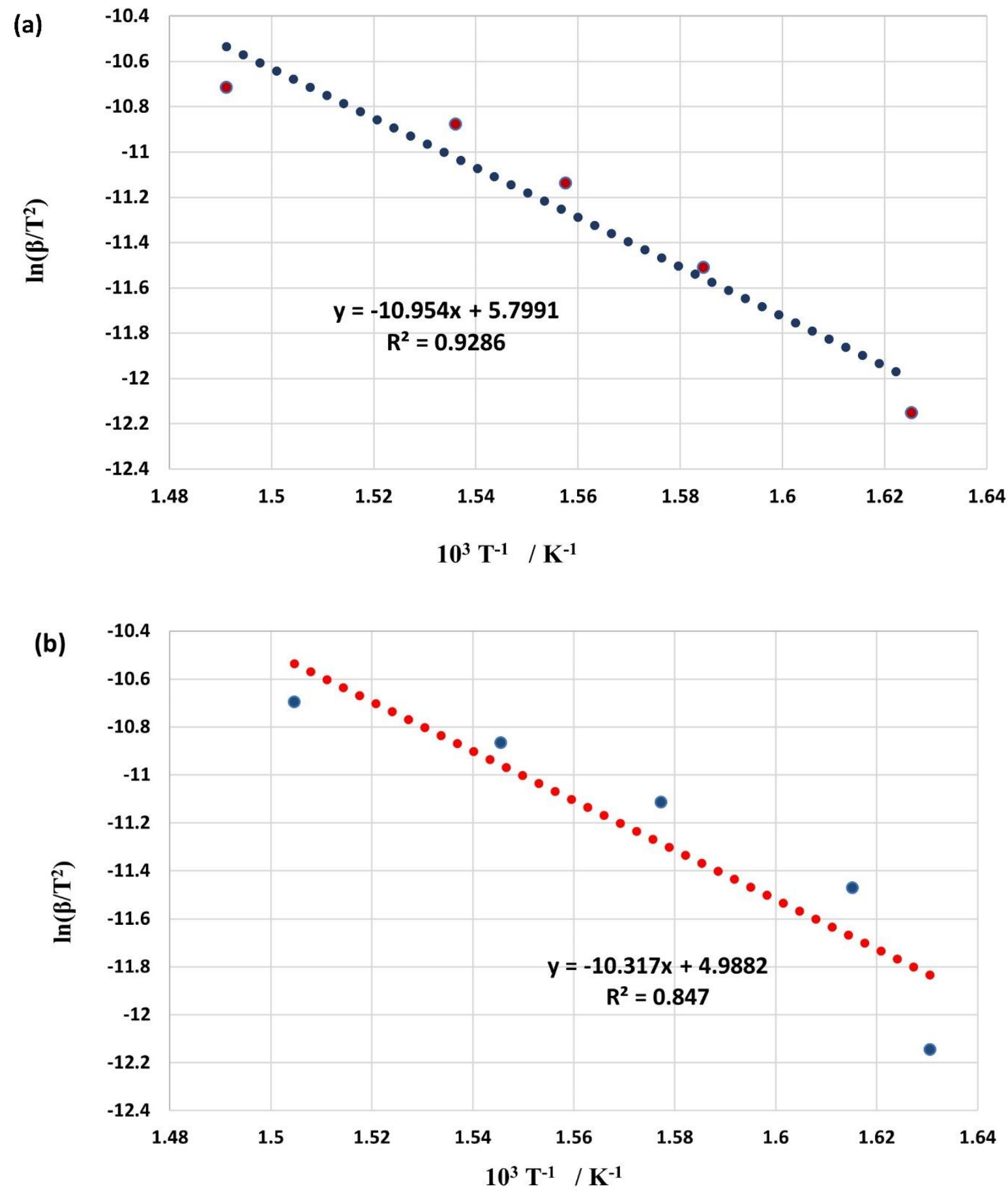

Figure 18. Determination of activation energy of combustion of AP(a), MIL-88B(Fe)/AP (b), using the Kissinger method.

The activation energies of the combustion reaction of $\mathrm{AP}$ and $\mathrm{MOF} / \mathrm{AP}$ were found to be $92.1 \mathrm{~kJ}$ $\mathrm{mol}^{-1}$ and $85.8 \mathrm{~kJ} \mathrm{~mol}^{-1}$, respectively. 


\subsubsection{Kinetic parameters obtained by the Kissinger-Akahira-Sunose (KAS) method}

Activation energy at different fractional conversions was determined using the modified Kissinger-Akahira-Sunose (KAS) method. The kinetics parameters, including pre-exponential factor $(A)$, kinetic model $(f(\alpha))$, the activation energy $\left(E_{a}\right)$, and a regression factor $(r)$ of AP and MOF/AP, are tabulated in Table 1.

Table 1: Kinetic data of un-activated AP and activated AP using the (KAS) method.

\begin{tabular}{c|ccc|c|c|c}
\hline \multirow{2}{*}{$\boldsymbol{\alpha}$ reacted } & \multicolumn{3}{c}{$\mathbf{A P}$} & \multicolumn{3}{|c}{ MIL-88B(Fe) MOF /AP } \\
\cline { 2 - 7 } & $\begin{array}{c}\mathbf{E a} \\
\left(\mathbf{k J ~ m o l}^{-\mathbf{1}}\right)\end{array}$ & $\begin{array}{c}\mathbf{L o g} \mathbf{A} \\
\left(\mathbf{s}^{-\mathbf{1}}\right)\end{array}$ & $\mathbf{r}$ & $\begin{array}{c}\mathbf{E a} \\
\left(\mathbf{k J ~ m o l}^{-\mathbf{1}}\right)\end{array}$ & $\begin{array}{c}\mathbf{L o g} \mathbf{A} \\
\left(\mathbf{s}^{-\mathbf{1}}\right)\end{array}$ & $\mathbf{r}$ \\
\hline 0.05 & 90 & 15 & 0.982 & 85 & 19 & 0.993 \\
\hline 0.10 & 92 & 17 & 0.993 & 86 & 18 & 0.997 \\
\hline 0.15 & 93 & 13 & 0.987 & 87 & 17 & 0.998 \\
\hline 0.20 & 95 & 14 & 0.989 & 88 & 18 & 0.995 \\
\hline 0.25 & 96 & 17 & 0.992 & 87 & 17 & 0.987 \\
\hline 0.30 & 89 & 15 & 0.992 & 86 & 16 & 0.998 \\
\hline 0.35 & 90 & 16 & 0.988 & 85 & 19 & 0.998 \\
\hline 0.40 & 95 & 14 & 0.995 & 86 & 18 & 0.997 \\
\hline 0.45 & 92 & 13 & 0.996 & 87 & 18 & 0.998 \\
\hline 0.50 & 93 & 14 & 0.998 & 87 & 17 & 0.997 \\
\hline 0.55 & 94 & 15 & 0.996 & 86 & 17 & 0.988 \\
\hline 0.60 & 95 & 16 & 0.995 & 85 & 19 & 0.997 \\
\hline 0.65 & 92 & 17 & 0.998 & 87 & 17 & 0.996 \\
\hline 0.70 & 93 & 18 & 0.998 & 88 & 19 & 0.997 \\
\hline 0.75 & 94 & 19 & 0.999 & 86 & 17 & 0.996 \\
\hline 0.80 & 95 & 14 & 0.998 & 87 & 18 & 0.998 \\
\hline 0.85 & 94 & 15 & 0.999 & 87 & 19 & 0.997 \\
\hline 0.90 & 94 & 14 & .999 & 86 & 19 & 0.998 \\
\hline Mean & $\mathbf{9 3 . 1}$ & $\mathbf{1 5 . 3}$ & & $\mathbf{8 7 . 2}$ & $\mathbf{1 6 . 8}$ & \\
\hline
\end{tabular}

The mean value of the activation energies of AP and MOF/ AP were found to be $93.1 \mathrm{~kJ} \mathrm{~mol}^{-1}$ and $87.2 \mathrm{~kJ} \mathrm{~mol}^{-1}$, respectively. Activation energies determined using the KAS method were found to be in reasonable agreement with the values established using Kissinger method. 


\section{Conclusions}

Iron-based MIL-88B metal-organic framework was synthesized following a facile microwaveassisted method with high power input at $850 \mathrm{~W}$, resulting in uniform size distribution in the range of few microns for a total synthesis time of $15 \mathrm{~min}$. The structure of the achieved flexible MOF was confirmed via XRD, SEM-EDX, TEM, $\mathrm{N}_{2}$ adsorption. Furthermore, the results showed that most of the produced MOF crystals were of a hexagonal bipyramidal diamond-like shape with the presence of some short spindle-like ones. The MIL- $88 \mathrm{~B}(\mathrm{Fe})$ structure showed high thermal stability above $300{ }^{\circ} \mathrm{C}$ and high $\mathrm{Fe}$ and $\mathrm{O}_{2}$ content of $24 \%$ and $29 \%$, respectively, suggesting the potential use of such a MOF in catalytic applications in the field of energetic materials. The XRD pattern for the MIL-88B(Fe) framework TGA air oxidation products confirmed the formation of an $\alpha-\mathrm{Fe}_{2} \mathrm{O}_{3}$-nanocatalyst as a final product. The catalytic efficiency of MIL-88B (Fe) on AP thermal behavior was assessed via DSC and TGA. AP solely has a decomposition enthalpy of 733 $\mathrm{J} \mathrm{g}^{-1}$, while the AP/MIL-88B(Fe) composite offered an increased decomposition enthalpy by $66 \%$; the main exothermic decomposition temperature was decreased by $71{ }^{\circ} \mathrm{C}$. Besides, MIL- $88 \mathrm{~B}(\mathrm{Fe})$ resulted in a decrease in the AP activation energy by $23 \%$ and $25 \%$ according to the Kissinger and KAS models, respectively.

\section{Acknowledgment}

We are thankful to the Arab Republic of Egypt - Ministry of Defense, for providing financial support to M. Y. Zorainy. The authors are also grateful to the Natural Sciences and Engineering Research Council of Canada (NSERC) for its support, as well as to the Fonds de Recherche du Québec - Nature et Technologies (FRQNT). This research was undertaken, in part, thanks to funding from the Canada Research Chair program.

\section{References}

[1] M. Alhamami, H. Doan, and C.-H. Cheng, "A Review on Breathing Behaviors of Metal-OrganicFrameworks (MOFs) for Gas Adsorption," Materials, vol. 7, no. 4, pp. 3198-3250, 2014, doi: https://doi.org/10.3390/ma7043198.

[2] H. Li, K. Wang, Y. Sun, C. T. Lollar, J. Li, and H.-C. Zhou, "Recent advances in gas storage and separation using metal-organic frameworks," Materials Today, vol. 21, no. 2, pp. 108-121, 2018, doi: https://doi.org/10.1016/j.mattod.2017.07.006.

[3] B. Li, H. M. Wen, Y. Yu, Y. Cui, W. Zhou, B. Chen, and G. Qian, "Nanospace within metal-organic frameworks for gas storage and separation," Materials Today Nano, vol. 2, pp. 21-49, 2018, doi: https://doi.org/10.1016/j.mtnano.2018.09.003.

[4] J.-R. Li, R. J. Kuppler, and H.-C. Zhou, "Selective gas adsorption and separation in metal-organic frameworks," Chemical Society Reviews, vol. 38, no. 5, pp. 1477-1504, 2009, doi: https://doi.org/10.1039/B802426J.

[5] X. Zhao, Y. Wang, D.-S. Li, X. Bu, and P. Feng, "Metal-Organic Frameworks for Separation," Advanced Materials, vol. 30, no. 37, p. 1705189, 2018, doi: https://doi.org/10.1002/adma.201705189. 
[6] A. Bavykina, N. Kolobov, I. S. Khan, J. A. Bau, A. Ramirez, and J. Gascon, "Metal-Organic Frameworks in Heterogeneous Catalysis: Recent Progress, New Trends, and Future Perspectives," Chemical Reviews, vol. 120, no. 16, pp. 8468-8535, 2020, doi: https://doi.org/10.1021/acs.chemrev.9b00685.

[7] V. R. Remya and M. Kurian, "Synthesis and catalytic applications of metal-organic frameworks: a review on recent literature," International Nano Letters, vol. 9, no. 1, pp. 17-29, 2019, doi: https://doi.org/10.1007/s40089-018-0255-1.

[8] L. Öhrström and F. M. A. Noa, Eds. Metal-Organic Frameworks (ACS In Focus. American Chemical Society, 2020. [Online]. Available: https://doi.org/10.1021/acs.infocus.7e4004.

[9] S. Horike, S. S. Nagarkar, T. Ogawa, and S. Kitagawa, "A New Dimension for Coordination Polymers and Metal-Organic Frameworks: Towards Functional Glasses and Liquids," Angewandte Chemie International Edition, vol. 59, no. 17, pp. 6652-6664, 2020, doi: https://doi.org/10.1002/anie.201911384.

[10] Z. Chang, D.-H. Yang, J. Xu, T.-L. Hu, and X.-H. Bu, "Flexible Metal-Organic Frameworks: Recent Advances and Potential Applications," Advanced Materials, vol. 27, no. 36, pp. 5432-5441, 2015, doi: https://doi.org/10.1002/adma.201501523.

[11] A. Li, R. B. Perez, S. Wiggin, S. C. Ward, P. A. Wood, and D. Fairen-Jimenez, "The launch of a freely accessible MOF CIF collection from the CSD," Matter, vol. 4, no. 4, pp. 1105-1106, 2021, doi: https://doi.org/10.1016/j.matt.2021.03.006.

[12] C. Serre, F. Millange, S. Surblé, and G. Férey, "A Route to the Synthesis of Trivalent TransitionMetal Porous Carboxylates with Trimeric Secondary Building Units," Angewandte Chemie International Edition, vol. 43, no. 46, pp. 6285-6289, 2004, doi: https://doi.org/10.1002/anie.200454250.

[13] S. Surblé, C. Serre, C. Mellot-Draznieks, F. Millange, and G. Férey, "A new isoreticular class of metal-organic-frameworks with the MIL-88 topology," Chemical Communications, no. 3, pp. 284286, 2006, doi: http://doi.org/10.1039/B512169H.

[14] C. Mellot-Draznieks, C. Serre, S. Surblé, N. Audebrand, and G. Férey, "Very Large Swelling in Hybrid Frameworks: A Combined Computational and Powder Diffraction Study," Journal of the American Chemical Society, vol. 127, no. 46, pp. 16273-16278, 2005, doi: https://doi.org/10.1021/ja054900x.

[15] C. Serre, C. Mellot-Draznieks, S. Surblé, N. Audebrand, Y. Filinchuk, and G. Férey, "Role of SolventHost Interactions That Lead to Very Large Swelling of Hybrid Frameworks," Science, vol. 315, no. 5820, pp. 1828-1831, 2007, doi: https://doi.org/10.1126/science.1137975.

[16] M. Ma, A. Bétard, I. Weber, N. S. Al-Hokbany, R. A. Fischer, and N. Metzler-Nolte, "Iron-Based Metal-Organic Frameworks MIL-88B and NH2-MIL-88B: High Quality Microwave Synthesis and Solvent-Induced Lattice "Breathing"," Crystal Growth \& Design, vol. 13, no. 6, pp. 2286-2291, 2013, doi: https://doi.org/10.1021/cg301738p.

[17] M. Ma, H. Noei, B. Mienert, J. Niesel, E. Bill, M. Muhler, R. A. Fischer, Y. Wang, U. Schatzschneider, and N. Metzler-Nolte, "Iron Metal-Organic Frameworks MIL-88B and NH2-MIL-88B for the Loading and Delivery of the Gasotransmitter Carbon Monoxide," Chemistry-A European Journal, vol. 19, no. 21, pp. 6785-6790, 2013, doi: https://doi.org/10.1002/chem.201201743.

[18] X. Cai, J. Lin, and M. Pang, "Facile Synthesis of Highly Uniform Fe-MIL-88B Particles," Crystal Growth \& Design, vol. 16, no. 7, pp. 3565-3568, 2016, doi: https://doi.org/10.1021/acs.cgd.6b00313.

[19] X. Liao, F. Wang, F. Wang, Y. Cai, Y. Yao, B.-T. Teng, Q. Hao, and L. Shuxiang, "Synthesis of (100) surface oriented MIL-88A-Fe with rod-like structure and its enhanced fenton-like performance for phenol removal," Applied Catalysis B: Environmental, vol. 259, p. 118064, 2019, doi: https://doi.org/10.1016/j.apcatb.2019.118064. 
[20] P. D. C. Dietzel, R. Blom, and H. Fjellvåg, "A scandium coordination polymer constructed from trimeric octahedral building blocks and 2,5-dihydroxyterephthalate," Dalton Transactions, no. 17, pp. 2055-2057, 2006, doi: https://doi.org/10.1039/B516365J.

[21] I. A. Ibarra, X. Lin, S. Yang, A. J. Blake, G. S. Walker, S. A. Barnett, D. R. Allan, N. R. Champness, P. Hubberstey, and M. Schröder, "Structures and H2 Adsorption Properties of Porous Scandium Metal-Organic Frameworks," Chemistry - A European Journal, vol. 16, no. 46, pp. 13671-13679, 2010, doi: https://doi.org/10.1002/chem.201000926.

[22] J. P. S. Mowat, S. R. Miller, A. M. Z. Slawin, V. R. Seymour, S. E. Ashbrook, and P. A. Wright, "Synthesis, characterisation and adsorption properties of microporous scandium carboxylates with rigid and flexible frameworks," Microporous and Mesoporous Materials, vol. 142, no. 1, pp. 322-333, 2011, doi: https://doi.org/10.1016/j. micromeso.2010.12.016.

[23] F. Carson, J. Su, A. E. Platero-Prats, W. Wan, Y. Yun, L. Samain, and X. Zou, "Framework Isomerism in Vanadium Metal-Organic Frameworks: MIL-88B(V) and MIL-101(V)," Crystal Growth \& Design, vol. 13, no. 11, pp. 5036-5044, 2013, doi: https://doi.org/10.1021/cg4012058.

[24] M. R. Mian, U. Afrin, M. S. Fataftah, K. B. Idrees, T. Islamoglu, D. E. Freedman, and O. K. Farha, "Control of the Porosity in Manganese Trimer-Based Metal-Organic Frameworks by Linker Functionalization," Inorganic Chemistry, vol. 59, no. 12, pp. 8444-8450, 2020, doi: https://doi.org/10.1021/acs.inorgchem.0c00885.

[25] S. Hou, Y.-n. Wu, L. Feng, W. Chen, Y. Wang, C. Morlay, and F. Li, "Green synthesis and evaluation of an iron-based metal-organic framework MIL-88B for efficient decontamination of arsenate from water," Dalton Transactions, vol. 47, no. 7, pp. 2222-2231, 2018, doi: https://doi.org/10.1039/C7DT03775A.

[26] V. Sintya, A. Saefumillah, and A. Zulys, "Development study of iron-based metal organic frameworks (Fe-based MOFs) as a binding agent in diffusive gradient in thin film method (DGT) for phos phate adsorption," IOP Conference Series: Materials Science and Engineering, vol. 902, p. 012026, 2020, doi: https://doi.org/10.1088/1757-899x/902/1/012026.

[27] A. Kumari, Mehilal, S. Jain, M. K. Jain, and B. Bhattacharya, "Nano-Ammonium Perchlorate: Preparation, Characterization, and Evaluation in Composite Propellant Formulation," Journal of Energetic Materials, vol. 31, no. 3, pp. 192-202, 2013, doi: https://doi.org/10.1080/07370652.2012.694576.

[28] S. Jain, M. Mehilal, S. Nandagopal, P. Singh, K. Radhakrishnan, and B. Bhattacharya, "Size and shape of ammonium perchlorate and their influence on properties of composite propellant," Defence Science Journal, vol. 59, no. 3, p. 294, 2009, doi: https://doi.org/10.14429/dsj.59.1523.

[29] P. A. Figueiredo and F. M. Brójo, "Theoretical analysis of a mmonium-perchlorate based composite propellants containing small size particles of boron," Energy Procedia, vol. 136, pp. 202-207, 2017, doi: https://doi.org/10.1016/j.egypro.2017.10.320.

[30] A. Manash and P. Kumar, "Comparison of burn rate and thermal decomposition of AP as oxidizer and PVC and HTPB as fuel binder based composite solid propellants," Defence Technology, vol. 15, no. 2, pp. 227-232, 2019, doi: https://doi.org/10.1016/j.dt.2018.08.010.

[31] W. Cai, P. Thakre, and V. Yang, "A Model of AP/HTPB Composite Propellant Combustion in RocketMotor Environments, " Combustion Science and Technology, vol. 180, no. 12, pp. 2143-2169, 2008, doi: https://doi.org/10.1080/00102200802414915.

[32] J. L. Arroyo, P. Povea, R. Faúndez, M. B. Camarada, C. Cerda-Cavieres, G. Abarca, J. M. Manriquez, and C. Morales-Verdejo, "Influence iron-iron distance on the thermal decomposition of ammonium perchlorate. New catalysts for the highly efficient combustion of solid rocket propellant," Journal of Organometallic Chemistry, vol. 905, p. 121020, 2020, doi: https://doi.org/10.1016/j.jorganchem.2019.121020. 
[33] G. P. Li, L. H. Shen, B. M. Zheng, M. Xia, and Y. J. Luo, "The preparation and properties of AP-based nano-limit growth energetic materials," in Advanced Materials Research, 2014, vol. 924: Trans Tech Publ, pp. 105-109, doi: https://doi. org/10.4028/www.scientific.net/AMR.924.105.

[34] W. Pang, L. T. De Luca, X. Fan, F. Maggi, H. Xu, W. Xie, and X. Shi, "Effects of Different Nano-Sized Metal Oxide Catalysts on the Properties of Composite Solid Propellants," Combustion Science and Technology, vol. 188, no. 3, pp. 315-328, 2016, doi: https://doi.org/10.1080/00102202.2015.1083986.

[35] S. Chaturvedi and P. N. Dave, "A review on the use of nanometals as catalysts for the thermal decomposition of ammonium perchlorate," Journal of Saudi Chemical Society, vol. 17, no. 2, pp. 135-149, 2013, doi: https://doi.org/10.1016/j.jscs.2011.05.009.

[36] S. Elbasuney and M. Yehia, "Ammonium Perchlorate Encapsulated with TiO2 Nanocomposite for Catalyzed Combustion Reactions," Journal of Inorganic and Organometallic Polymers and Materials, vol. 29, no. 4, pp. 1349-1357, 2019, doi: https://doi.org/10.1007/s10904-019-01099-y.

[37] S. Elbasuney and M. Yehia, "Thermal decomposition of ammonium perchlorate catalyzed with CuO nanoparticles," Defence Technology, vol. 15, no. 6, pp. 868-874, 2019, doi: https://doi.org/10.1016/j.dt.2019.03.004.

[38] M. Zou, X. Jiang, L. Lu, and X. Wang, "Nano or micro? A mechanism on thermal decomposition of ammonium perchlorate catalyzed by cobalt oxalate," Journal of Hazardous Materials, vol. 225226, pp. 124-130, 2012, doi: https://doi.org/10.1016/j.jhazmat.2012.05.010.

[39] S. S. Joshi, P. R. Patil, and V. Krishnamurthy, "Thermal Decomposition of Ammonium Perchlorate in the Presence of Nanosized Ferric Oxide," Defence Science Journal, vol. 58, no. 6, 2008, doi: https://doi.org/10.14429/dsj.58.1699.

[40] S. Elbasuney and M. Yehia, "Ferric Oxide Colloid: A Novel Nano-catalyst for Solid Propellants," Journal of Inorganic and Organometallic Polymers and Materials, vol. 30, no. 3, pp. 706-713, 2020, doi: https://10.1007/s10904-019-01339-1.

[41] S. Chaturvedi and P. N. Dave, "Nano-metal oxide: potential catalyst on thermal decomposition of ammonium perchlorate," Journal of Experimental Nanoscience, vol. 7, no. 2, pp. 205-231, 2012, doi: https://doi.org/10.1080/17458080.2010.517571.

[42] J. Klinowski, F. A. Almeida Paz, P. Silva, and J. Rocha, "Microwave-Assisted Synthesis of MetalOrganic Frameworks," Dalton Transactions, vol. 40, no. 2, pp. 321-330, 2011, doi: https://doi.org/10.1039/CODT00708K.

[43] N. A. Khan and S. H. Jhung, "Synthesis of metal-organic frameworks (MOFs) with microwave or ultrasound: Rapid reaction, phase-selectivity, and size reduction," Coordination Chemistry Reviews, vol. 285, pp. 11-23, 2015, doi: https://doi.org/10.1016/j.ccr.2014.10.008.

[44] A. Yurduşen and Y. Yürüm, "A Controlled Synthesis Strategy To Enhance the CO2 Adsorption Capacity of MIL-88B Type MOF Crystallites by the Crucial Role of Narrow Micropores," Industrial \& Engineering Chemistry Research, vol. 58, no. 31, pp. 14058-14072, 2019, doi: http://doi.org/10.1021/acs.iecr.9b01653.

[45] S. Xiong, X. Lin, S. Liu, S. Weng, S. Jiang, Y. Jiao, Y. Xu, and J. Cheng, "Metal-organic framework derived $\alpha$-Fe2O3 nano-octahedron with oxygen vacancies for realizing outstanding energy storage performance," Vacuum, vol. 182, p. 109692, 2020, doi: https://doi.org/10.1016/j.vacuum.2020.109692.

[46] A. Banerjee, V. Aravindan, S. Bhatnagar, D. Mhamane, S. Madhavi, and S. Ogale, "Superior lithium storage properties of $\alpha$-Fe2O3 nano-assembled spindles," Nano Energy, vol. 2, no. 5, pp. 890-896, 2013, doi: https://doi.org/10.1016/j.nanoen.2013.03.006.

[47] Y. Pang, Z. Li, X. Jiao, D. Chen, and C. Li, "Metal-Organic Framework Derived Porous a-Fe2O3/C Nano-shuttles for Enhanced Visible-light Photocatalysis," ChemistrySelect, vol. 5, no. 3, pp. 10471053, 2020, doi: https://doi.org/10.1002/slct.201904021. 
[48] A. Khawam and D. R. Flanagan, "Basics and Applications of Solid-State Kinetics: A Pharmaceutical Perspective," Journal of Pharmaceutical Sciences, vol. 95, no. 3, pp. 472-498, 2006, doi: https://doi.org/10.1002/jps.20559.

[49] D. Trache, A. Abdelaziz, and B. Siouani, "A simple and linear isoconversional method to determine the pre-exponential factors and the mathematical reaction mechanism functions," Journal of Thermal Analysis and Calorimetry, vol. 128, no. 1, pp. 335-348, 2017, doi: https://doi.org/10.1007/s10973-016-5962-0.

[50] S. Vyazovkin, A. K. Burnham, J. M. Criado, L. A. Pérez-Maqueda, C. Popescu, and N. Sbirrazzuoli, "ICTAC Kinetics Committee recommendations for performing kinetic computations on thermal analysis data," Thermochimica Acta, vol. 520, no. 1, pp. 1-19, 2011, doi: https://doi.org/10.1016/j.tca.2011.03.034.

[51] D. Trache, K. Khimeche, A. Mezroua, and M. Benziane, "Physicochemical properties of microcrystalline nitrocellulose from Alfa grass fibres and its thermal sta bility, "Journal of Thermal Analysis and Calorimetry, vol. 124, no. 3, pp. 1485-1496, 2016, doi: https://doi.org/10.1007/s10973-016-5293-1.

[52] T. Akahira and T. Sunose, "Joint Convention of Four Electrical Institutes," Chiba Institute of Technology, Chiba, 1971, vol. 16, pp. 22-31.

[53] R. Fazaeli, H. Aliyan, M. Moghadam, and M. Masoudinia, "Nano-rod catalysts: Building MOF bottles (MIL-101 family as heterogeneous single-site catalysts) around vanadium oxide ships," Journal of Molecular Catalysis A: Chemical, vol. 374-375, pp. 46-52, 2013, doi: https://doi.org/10.1016/j. molcata.2013.03.020.

[54] T. A. Vu, G. H. Le, C. D. Dao, L. Q. Dang, K. T. Nguyen, P. T. Dang, H. T. K. Tran, Q. T. Duong, T. V. Nguyen, and G. D. Lee, "Isomorphous substitution of $\mathrm{Cr}$ by Fe in MIL-101 framework and its application as a novel heterogeneous photo-Fenton catalyst for reactive dye degradation," RSC Advances, vol. 4, no. 78, pp. 41185-41194, 2014, doi: https://doi.org/10.1039/C4RA06522K.

[55] E. Elsayed, P. Anderson, R. Al-Dadah, S. Mahmoud, and A. Elsayed, "MIL-101(Cr)/calcium chloride composites for enhanced adsorption cooling and water desalination," Journal of Solid State Chemistry, vol. 277, pp. 123-132, 2019, doi: https://doi.org/10.1016/j.jssc.2019.05.026.

[56] H. Su, J. Lv, L. Yang, L. Feng, Y. Liu, Z. Du, and L. Zhang, "Rapid and selective adsorption of a typical aromatic organophosphorus flame retardant on MIL-101-based metal-organic frameworks, "RSC Advances, vol. 10, no. 4, pp. 2198-2208, 2020, doi: https://doi.org/10.1039/C9RA09062B.

[57] M. Lammert, S. Bernt, F. Vermoortele, D. E. De Vos, and N. Stock, "Single- and Mixed-Linker CrMIL-101 Derivatives: A High-Throughput Investigation," Inorganic Chemistry, vol. 52, no. 15, pp. 8521-8528, 2013, doi: https://doi.org/10.1021/ic4005328.

[58] M. Sheikh Alivand, N. H. M. Hossein Tehrani, M. Shafiei-alavijeh, A. Rashidi, M. Kooti, A. Pourreza, and S. Fakhraie, "Synthesis of a modified HF-free MIL-101(Cr) nanoadsorbent with enhanced $\mathrm{H} 2 \mathrm{~S} / \mathrm{CH} 4, \mathrm{CO} 2 / \mathrm{CH} 4$, and $\mathrm{CO} 2 / \mathrm{N} 2$ selectivity," Journal of Environmental Chemical Engineering, vol. 7, no. 2, p. 102946, 2019, doi: https://doi.org/10.1016/j.jece.2019.102946.

[59] M. Asiabi, A. Mehdinia, and A. Jabbari, "Electrospun biocompatible Chitosan/MIL-101 (Fe) composite nanofibers for solid-phase extraction of $\Delta 9$-tetrahydrocannabinol in whole blood samples using Box-Behnken experimental design," Journal of Chromatography A, vol. 1479, pp. 71-80, 2017, doi: https://doi.org/10.1016/j.chroma.2016.12.024.

[60] Y. Liu, Y. Xie, M. Dai, Q. Gong, and Z. Dang, "Ag/AgCl/MIL-101(Fe) Catalyzed Degradation of Methylene Blue under Visible Light Irradation," Materials, vol. 12, no. 9, p. 1453, 2019, doi: https://doi.org/10.3390/ma12091453.

[61] A. Dhakshinamoorthy, M. Alvaro, H. Chevreau, P. Horcajada, T. Devic, C. Serre, and H. Garcia, "Iron(iii) metal-organic frameworks as solid Lewis acids for the isomerization of $\alpha$-pinene oxide," 
Catalysis Science \& Technology, vol. 2, no. 2, pp. 324-330, 2012, doi: https://doi.org/10.1039/C2CY00376G.

[62] E. Rahmani and M. Rahmani, "Alkylation of benzene over Fe-based metal organic frameworks (MOFs) at low temperature condition," Microporous and Mesoporous Materials, vol. 249, pp. 118127, 2017, doi: https://doi.org/10.1016/j.micromeso.2017.04.058.

[63] K. S. Walton and R. Q. Snurr, "Applicability of the BET Method for Determining Surface Areas of Microporous Metal-Organic Frameworks," Journal of the American Chemical Society, vol. 129, no. 27, pp. 8552-8556, 2007, doi: https://doi.org/10.1021/ja071174k.

[64] Y.-S. Bae, A. Ö. Yazaydın, and R. Q. Snurr, "Evaluation of the BET Method for Determining Surface Areas of MOFs and Zeolites that Contain Ultra-Micropores," Langmuir, vol. 26, no. 8, pp. 54755483, 2010, doi: https://doi.org/10.1021/la100449z.

[65] J. Rouquerol, P. Llewellyn, and F. Rouquerol, "Is the bet equation applicable to microporous adsorbents?," in Studies in Surface Science and Catalysis, vol. 160: Elsevier, 2007, pp. 49-56.

[66] A. Schneemann, V. Bon, I. Schwedler, I. Senkovska, S. Kaskel, and R. A. Fischer, "Flexible metalorganic frameworks," Chemical Society Reviews, vol. 43, no. 16, pp. 6062-6096, 2014, doi: https://doi.org/10.1039/C4CS00101J.

[67] G.-T. Vuong, M.-H. Pham, and T.-O. Do, "Synthesis and engineering porosity of a mixed metal Fe2Ni MIL-88B metal-organic framework," Dalton Transactions, vol. 42, no. 2, pp. 550-557, 2013, doi: https://doi.org/10.1039/C2DT32073H.

[68] J. Wang, J. Wan, Y. Ma, Y. Wang, M. Pu, and Z. Guan, "Metal-organic frameworks MIL-88A with suitable synthesis conditions and optimal dosage for effective catalytic degradation of Orange $\mathrm{G}$ through persulfate activation," RSC Advances, vol. 6, no. 113, pp. 112502-112511, 2016, doi: https://doi.org/10.1039/C6RA24429G.

[69] B. Wu, J. Fu, Y. Zhou, S. Luo, Y. Zhao, G. Quan, X. Pan, and C. Wu, "Tailored core-shell dual metalorganic frameworks as a versatile nanomotor for effective synergistic antitumor therapy," Acta Pharmaceutica Sinica B, vol. 10, no. 11, pp. 2198-2211, 2020/11/01/ 2020, doi: https://doi.org/10.1016/j.apsb.2020.07.025.

[70] A. Yurduşen, A. Yürüm, and Y. Yürüm, "Engineering MIL-88B crystallites for enhanced $\mathrm{H} 2$ uptake capacity: The role of ultramicropores," InternationalJournal of Energy Research, vol. 44, no. 4, pp. 2875-2888, 2020, doi: https://doi.org/10.1002/er.5104.

[71] S. Abednatanzi, P. Gohari Derakhshandeh, H. Depauw, F.-X. Coudert, H. Vrielinck, P. Van Der Voort, and K. Leus, "Mixed-metal metal-organic frameworks," Chemical Society Reviews, vol. 48, no. 9, pp. 2535-2565, 2019, doi: https://doi.org/10.1039/C8CS00337H. 


\section{Statements and Declarations}

\section{Funding}

This work was supported by Natural Sciences and Engineering Research Council of Canada (NSERC) as well as the Fonds de Recherche du Québec - Nature et Technologies (FRQNT). This research was undertaken, in part, thanks to funding from the Canada Research Chair program. Author M. Y. Zorainy has received research support from Arab Republic of Egypt- Ministry of Defense.

\section{Competing Interest}

No potential competing interest was reported by the authors.

\section{Author Contributions}

MYZ: Conceptualization, Data curation, Formal Analysis, Funding acquisition, Investigation, Methodology, Validation, Visualization, Writing - original draft, Writing - review \& editing.

MG: Conceptualization, Data curation, Formal Analysis, Investigation, Methodology, Resources, Validation, Visualization, Writing - original draft, Writing - review \& editing.

SE: Conceptualization, Data curation, Formal Analysis, Investigation, Methodology, Resources, Software, Validation, Visualization, Writing - original draft, Writing - review \& editing.

SK: Conceptualization, Investigation, Methodology, Resources, Supervision, Validation, Writing - review \& editing.

DCB: Conceptualization, Funding acquisition, Investigation, Project administration, Resources, Supervision, Validation, Writing - review \& editing.

\section{Data Availability}

The datasets generated during and/or analysed during the current study are available from the corresponding author on reasonable request. 


\section{Supplementary Files}

This is a list of supplementary files associated with this preprint. Click to download.

- Supportinglnformation.pdf 